\title{
Price Dispersion and Inflation: New Facts and Theoretical Implications
}

\author{
Viacheslav Sheremirov
}

\begin{abstract}
:
In macroeconomic models, the level of price dispersion-which is typically approximated through its relationship with inflation -is a central determinant of welfare, the cost of business cycles, the optimal rate of inflation, and the tradeoff between inflation and output stability. While the comovement of price dispersion and inflation implied by standard models is positive, I find that in the data, it is negative. This is due to transitory price changes (sales): if sales are removed from the data, the comovement of price dispersion and inflation turns positive. Nevertheless, I show that a wide variety of price-stickiness models that ignore sales cannot quantitatively match the comovement even for regular prices. Modeling sales explicitly helps to reconcile theory with the data: a Calvo model with sales quantitatively matches both the negative comovement for posted prices and the positive comovement for regular prices. Thus, sales play a pivotal role in explaining the properties of regular prices; models without salesfailing to reproduce fundamental properties of price dispersion-may significantly mismeasure welfare and its determinants.
\end{abstract}

\section{JEL Classifications: E17, E31, E37, E40, E52}

\section{Keywords: inflation, price dispersion, sales, sticky prices}

Viacheslav Sheremirov is an economist in the research department of the Federal Reserve Bank of Boston. His email address is viacheslav.sheremirov@bos.frb.org.

I would like to express my sincere gratitude to Yuriy Gorodnichenko for his invaluable advice, guidance, and support during the project; as well as to Benjamin Faber, Amir Kermani, Demian Pouzo, Andrés Rodríguez-Clare, and especially to Olivier Coibion, Pierre-Olivier Gourinchas, Marurice Obstfeld, and David Romer for detailed comments and suggestions; to my fellow graduate students at UC Berkeley (especially to Vladimir Asriyan, David Berger, and Yury Yatsynovich) for numerous conversations on the topic; and to seminar participants at UNC Chapel Hill, the Bank of Canada, the Federal Reserve Bank of Boston, Simon Fraser University, the University of Illinois at UrbanaChampaign, the Federal Reserve Bank of Cleveland, Cornerstone Research at Washington, DC, the College of William and Mary, Vanderbilt University, UC Irvine, UH Manoa, and UC Berkeley for comments and discussion. I also gratefully acknowledge support from the UC Berkeley Graduate Division Summer Grant, which I received while a graduate student there. I am also grateful to Sandra Spirovska for excellent research assistance and to Suzanne Lorant for superb editorial assistance.

This paper, which may be revised, is available on the web site of the Federal Reserve Bank of Boston at http://www.bostonfed.org/economic/wp/index.htm.

The views expressed herein are those of the author and are not necessarily those of the Federal Reserve Bank of Boston or the Federal Reserve System.

This version: July 2015; first version: November 2013 


\section{Introduction}

Within a single week of June 2011, the price of a Gillette Venus Embrace razor with cartridge varied from \$4.99 to \$14.79 per unit across stores in the San Francisco Metropolitan Area-with a standard deviation of $\log$ prices of 0.32 ( 0.14 for regular prices, that is, sales excluded). Economists have long thought that price dispersion exists in equilibrium because, as Stigler (1961, p. 214) put it, "there is never absolute homogeneity in the commodity if we include the terms of sale within the concept of the commodity," and because shopping experience generally differs across stores. However, just a year earlier, in June 2010, weekly prices for the same razor in the same area varied only between $\$ 8.99$ and $\$ 12.59$, with a standard deviation of $\log$ prices of 0.12 (0.08 for regular prices). It is very unlikely that a difference in shopping experience across the same stores changed so much in a year. Examples like this are pervasive. What determines the level and time variation of price dispersion and what does it mean for aggregate analyses?

From a macroeconomic perspective, price rigidity is often perceived to be an important source of price dispersion, with significant implications for the dynamic properties of aggregate variables, welfare calculations, and the design of optimal policy. For instance, in standard New Keynesian models, the key cost of business cycles stems from the price dispersion resulting from firms' inability to adjust prices instantaneously. However, different macroeconomic models make conflicting predictions about the level of price dispersion, as well as about its dynamic properties and sensitivity to inflation. These contrasting predictions can help us to discriminate across alternative models. To the best of my knowledge, these predictions have not been tested before.

In this paper, I examine the link between price dispersion and inflation, and the role of sales in this relationship. The comovement of inflation and price dispersion sheds light on the degree of price rigidity and the type of frictions that prevail in the data. In particular, a higher degree of price rigidity implies a stronger response of price dispersion to inflation. The nature of frictions is important too: models with time-dependent frictions produce stronger responses of price dispersion to inflation than those with state-dependent frictions. Crucially, in models with time-dependent price adjustment (for example, Calvo 1983), monetary shocks affect real variables, while in state-dependent models with fixed menu costs (Golosov and Lucas 2007), the classical dichotomy holds—nominal variables do not affect real variables. I show that the Calvo model with sales can match the comovement of price dispersion and inflation found in the data, while purely state-dependent models cannot.

To start, I document the degree of cross-store price dispersion and its comovement with disaggregated inflation, using monthly data on prices and total sales in grocery and drug stores in 50 U.S. Metropolitan Statistical Areas (MSAs). Price dispersion is measured as the standard deviation of log prices of a good at the Universal Product Code (UPC) level over stores in a given MSA, aggregated to a market-category of goods level, with annual sales as weights. My major findings are the following: First, price dispersion is pervasive and cannot be fully explained by sales. The average standard deviation of log prices across stores over the period of 2001-2011 is $9.5 \mathrm{log}$ points for all prices and $6.6 \mathrm{log}$ points if sales are excluded. Second, I document the negative correlation between price dispersion and inflation at the location-category level, which is driven entirely by the presence of sales: the correlation between inflation and the dispersion of regular prices is positive. Third, local labor market characteristics, such as the unemployment rate or total employment, have only small effects on price dispersion, and do not change its relationship with inflation. 
Fourth, I find strong propagation in the response of price dispersion to inflation.

Next, I investigate whether standard macroeconomic models can account for these facts. I consider several popular models: (1) a workhorse New Keynesian model with time-dependent frictions in price adjustment as in Calvo (1983); and (2) a model with state-dependent pricing based on the fixed menu cost (FMC) assumption as in Golosov and Lucas (2007). These two models can be cast as a special case of a more general framework referred to as the smoothly state-dependent pricing (SSDP) developed in Costain and Nakov (2011a,b), which I test against the data as well. This allows me to nest the models and to isolate the effects of specific frictions in price adjustment. Finally, I examine the Calvo model with sales, based on Guimaraes and Sheedy (2011), to emphasize the role of sales in matching properties of price dispersion in the data.

I find that models without sales fail to match empirical findings even for regular prices. The Calvo model without sales overstates the comovement of price dispersion and inflation by a factor of 15 , while the FMC model understates it by a factor of 5. Intuitively, in time-dependent pricing models, most firms cannot adjust their prices in response to an inflationary shock, while those few that can adjust do so by a lot, thereby yielding a strong response of price dispersion and a small response of inflation. In contrast, in state-dependent pricing models, an inflationary shock moves firms outside the $(S, s)$ bounds and forces them to reset their prices, thereby inducing a strong impact on inflation and a weak impact on price dispersion. In fact, if menu costs are small, price dispersion may even decrease. Although the SSDP model is naturally closer to the data-as it combines time- and state-dependent frictions-the parameterization required to match the comovement of price dispersion and inflation is inconsistent with other evidence on the distribution of the sizes of price changes. ${ }^{1}$ In this model, pricing should be more state-dependent than is suggested by the data on the size of price changes. Thus, none of these models is consistent with the stylized facts of regular price dispersion documented in this paper.

I show that the best match of empirical findings, for both posted and regular prices, comes from a Calvo model with sales, calibrated to match the observed frequency of sales. Intuitively, sales in this model serve as a channel of additional price flexibility that does not interfere with the frequency of regular price changes. In order to match the comovement of price dispersion and inflation, the Calvo model without sales requires a much higher per-period probability of price adjustment than the one suggested by the frequency of regular price changes. In the SSDP model, pricing has to be more state-dependent, meaning it has less aggregate rigidity. The finding that the Calvo model with sales matches the properties of regular prices better than a similar model without sales implies that sales have an important interaction with regular prices that is lost when sales are omitted. This implication is at odds with the conclusions drawn by Guimaraes and Sheedy (2011) and Kehoe and Midrigan (2014), who argue that sales have little impact on macroeconomic dynamics and that Calvo models without sales capture the salient features of the data sufficiently. In contrast, this paper's results suggest that in order to capture the comovement of regular price dispersion and inflation, it is necessary to incorporate sales into macro models. Because in macroeconomic models the level and dynamics of price dispersion have direct implications for welfare, the cost of business cycles, and the optimal inflation rate, relying on models that are at odds with the empirical properties of price dispersion can lead to nontrivial mismeasurement of optimal policy actions.

This paper contributes to several strands of literature. First, it presents new empirical facts on the

\footnotetext{
${ }^{1}$ For more details on the role of small price changes, see Midrigan (2011).
} 
relationship between price dispersion and inflation. Second, it quantifies the comovement between the two in several prominent general equilibrium models. Third, it highlights the role of price dispersion in welfare calculations. Finally, it provides new evidence on the link between observed micro-pricing characteristics and structural parameters in the models.

This paper's empirical contribution is related to earlier attempts to track the comovement of price dispersion and inflation in the data, such as Van Hoomissen (1988) and Lach and Tsiddon (1992). Similar to this line of work, I look at cross-store price dispersion and sectoral inflation for fast-moving consumer goods across supermarkets. Unlike them, I find a negative correlation between the two. The difference can be explained by several factors: First, I look at grocery stores across the United States in the 2000s, while they focus on supermarkets in Israel in the 1970-1980s. Second, their data contain high-inflation episodes, while inflation is low to moderate in my sample. I conjecture that in my sample sales are more prevalent, driving the difference in results. Finally, the dataset used in this paper is much richer and more representative in terms of product and location coverage. ${ }^{2}$

Most of the empirical literature on price dispersion studies its micro-level determinants—the value of a good (Pratt, Wise, and Zeckhauser 1979), purchase frequency (Sorensen 2000), number of sellers (Baye, Morgan, and Scholten 2004)—or compare price dispersion in online markets to that in brick-and-mortar stores (Brynjolfsson and Smith 2000, Gorodnichenko, Sheremirov, and Talavera 2014). Some papers use testable predictions from industrial organization models to distinguish between them. ${ }^{3}$ Instead, in this paper, I focus on the comovement of price dispersion with aggregate variables. Similar to this study, a number of papers focus on the relationship of inflation and relative price variability (RPV), measured as the cross-sector standard deviation of inflation rates (Grier and Perry 1996, Debelle and Lamont 1997, Silver and Ioannidis 2001, Konieczny and Skrzypacz 2005, Choi 2010). However, this concept is different from price dispersion, as RPV measures the variability of prices across categories, while price dispersion measures it within categories. ${ }^{4}$

This paper also contributes to the literature on the theoretical relationship between inflation and price dispersion. Sheshinski and Weiss (1977) show that with the nominal cost of price adjustment, the correlation of inflation and price dispersion should be positive. Benabou $(1988,1992)$ combines frictions in price adjustment with search frictions, and reaches a similar conclusion. These models are cast in partial equilibrium and make mostly qualitative statements. In contrast, I consider general-equilibrium

\footnotetext{
${ }^{2}$ Van Hoomissen's dataset contains monthly observations for 13 uniquely defined goods in 1971-1984, while Lach and Tsiddon's data contain 26 food products in 1978-1984. In comparison, the dataset used in this paper covers 31 product categories with dozens of goods sold across 50 MSAs in the United States.

${ }^{3}$ For example, Lach (2002) finds evidence of temporal price dispersion, which arises in models with randomized strategies, such as Varian (1980) or Burdett and Judd (1983). Spatial price dispersion is instead a feature coming from heterogeneity across agents, as in Reinganum (1979) or MacMinn (1980).

${ }^{4}$ Most of the papers conclude that consistent with theory, there is a positive relationship between inflation and RPV; however, some papers question this result showing a negative, nonlinear, or unstable relationship between the two. Debelle and Lamont (1997) find a positive correlation between inflation and RPV in a sample of U.S. cities from the mid-1950s to the mid-1980s. The use of between-city variation helps to focus on nation-wide shocks. Konieczny and Skrzypacz (2005) support the result for Poland in the early 1990s, when inflation was high. The effect of expected inflation is found to be stronger than the effect of unexpected inflation. A few other papers, however, express their disagreement: (1) In a bivariate GARCH-M model, Grier and Perry (1996) show that inflation affects RPV only when inflation uncertainty is not controlled for. (2) Silver and Ioannidis (2001) estimate seemingly unrelated regressions for a sample of nine European countries in the 1980s, and find a negative correlation between unexpected inflation and RPV. (3) Choi (2010) looks at the data for the United States and Japan after 1970, and documents regime changes in the relationship of inflation and RPV, which is positive in high-inflation environments and nonlinear (U-shaped around a positive threshold) during the Great Moderation.
} 
models and measure the degree of the comovement quantitatively. I also identify models that can give rise to a negative correlation of inflation and price dispersion, contrary to their result.

Next, this paper provides new evidence on the type and size of frictions in price setting. In particular, to match the stylized facts on price dispersion in the models with time-dependent frictions, prices need to be more flexible than found in the literature (Nakamura and Steinsson 2008). For models that combine timeand state-dependent frictions (Costain and Nakov 2011a,b), my results imply that price-setting should be closer to state-dependent than it is in the models calibrated to match the distribution of the sizes of price changes. Finally, the paper's results suggest that sales might affect regular prices. A model with sales is shown to match the properties of regular prices that models without sales cannot.

Finally, my results suggest that papers that compute welfare in the Calvo setup (for instance, Coibion, Gorodnichenko, and Wieland 2012) should be more careful about choosing the right measure of price dispersion, as the degree of price dispersion and its comovement with inflation observed in the data are inconsistent with the Calvo model. Using the correct measure not only creates a level effect on welfare and the cost of business cycles, but also changes the shape of their relationship with trend inflation. This can result in a nontrivial effect on the estimates of optimal trend inflation.

The paper proceeds as follows. Section 2 describes the data and documents that the degree of price dispersion is large, even if sale prices are excluded. It further shows that the level of price dispersion does not change much across the types of stores or products, and that it cannot be fully explained by store fixed effects or chain-specific policies. Section 3 shows that in the data, price dispersion and inflation are negatively correlated, contradicting the models that emphasize price rigidity. The difference between the data and the models is attributed to the prevalence of sales: excluding sales reverts the correlation to positive. Section 4 lays out theoretical models of price rigidity that give rise to the relationship between inflation and price dispersion. Section 5 describes calibration and then presents the results from the simulations of the models laid out in Section 4. First, it analyzes the results' implication for our understanding of price setting. It demonstrates that neither models with purely time-dependent price setting nor the ones with purely state-dependent price setting can explain the comovement in the data. A model that combines the two frictions is closer to the data; however, for a given parameterization, it can match either the comovement or the distribution of the sizes of price changes, but not both. Then, Section 5 shows that including sales in the model not only improves its properties of posted prices, but also allows matching the comovement for regular prices. Hence, the interaction between sales and regular prices allows for more price flexibility without making counterfactual assumptions about the frequency of regular price changes. I provide a brief discussion and conclude in Section 6. 


\section{Price Dispersion in the Data}

Price dispersion is a salient feature of macroeconomic models with price or information rigidity. Yet, until recently, surprisingly little effort to quantify its amount in the data has been made. ${ }^{5}$ To track aggregateprice movements, government agencies and monetary authorities rely predominantly on the inflation rate. $^{6}$ Academic researchers look at the extensive and intensive margins of price adjustment (the frequency and size of price changes) or synchronization more than at price heterogeneity across retailers. Although recent research has shown that during recessions consumption reallocation often occurs along the price distribution (Coibion, Gorodnichenko, and Hong 2015), little is known about how the price distribution looks and whether it changes over time. This can be partially explained by the lack of data to consistently measure cross-sectional price distribution. Luckily, scanner data, which have become widely available recently, help to shed new light on this issue.

Microeconomic factors such as the elasticity of demand, retailers' market power, product characteristics, or store-specific costs are known to affect the degree of price dispersion (Gorodnichenko, Sheremirov, and Talavera 2014). This section, however, hints that such factors may have a limited effect on its aggregate properties. In particular, I find that the degree of price dispersion across drugstores is similar to that across grocery stores, despite the fact that drugstores charge a "convenience premium," indicating greater market power. The level of price dispersion is also roughly similar across food, beverage, and personal care items, all of which differ in demand elasticity and in the degree of storability, or across the categories of goods that differ in the perceived degree to which they can be stockpiled.

Although store-specific factors and chain-specific business strategies are found to play some role, alone they cannot explain the price dispersion observed in the data. In particular, price dispersion is only slightly larger across chains than across stores within the same chain. This finding may suggest that some chains cater to the segment of richer customers and therefore provide better amenities. Even after removing a store-specific component-which captures price differentials across chains and store-specific costs such as the costs stemming from the size and location-price dispersion decreases by less than 25 percent. This section proceeds by describing the data, and then explains how price dispersion is measured. Next, it documents the degree of price dispersion observed in the data, as well as its cross-sectional and time-series properties.

\subsection{Data Description}

To calculate price dispersion, I use scanner data provided by IRI, a market research company. ${ }^{7}$ This dataset, first described in Bronnenberg, Kruger, and Mela (2008), is well known to economists, and was previously used to address numerous questions on inflation dynamics (Chevalier and Kashyap 2011, Glandon 2011,

\footnotetext{
${ }^{5}$ Clark and Vincent (2014) and Kaplan and Menzio (2014) are notable exceptions, as far as scanner data from brick-and-mortar stores are concerned. There is more research on price dispersion in online markets (Brynjolfsson and Smith 2000, Chevalier and Goolsbee 2003, Baye, Morgan, and Scholten 2004), but except for Baye et al. (2009) and Gorodnichenko, Sheremirov, and Talavera (2014), which use data on clicks, few studies have data on a quantity margin. Cross-border price dispersion was recently studied by Boivin, Clark, and Vincent (2012) and Gorodnichenko and Talavera (2014).

${ }^{6}$ However, CPI inflation does not fully capture the effect of consumers switching to cheaper stores or actively searching for best prices (Chevalier and Kashyap 2011) during recession (Coibion, Gorodnichenko, and Hong 2015).

${ }^{7}$ I would like to thank IRI for making the data available. All estimates and analysis in this paper, based on data provided by IRI, are by the author and not by IRI.
} 
Nakamura, Nakamura, and Nakamura 2011, Gagnon, López-Salido, and Vincent 2013, Coibion, Gorodnichenko, and Hong 2015). With rich product and store coverage, 11 years of weekly price observations allow me to measure price dispersion accurately. The data contain units and total sales of consumer goods at the Universal Product Code (UPC) level across grocery and drug stores in the United States. The price therefore can be computed as a unit value index (total sales divided by units), widely used in the literature. ${ }^{8}$ The information whether a good was on sale in a given week is provided; however, no cost information is available.

The dataset covers 50 markets in the United States. In most cases, a market corresponds to a geographic location that is similar to an MSA. In some cases, it comprises stores located in two MSAs of the same state, of an entire state, or of a region that includes MSAs in at least two states. ${ }^{9}$ Fifteen of 17 MSAs with population of more than 3 million, based on the 2010 U.S. Census, are covered (no data provided for Miami, FL, or Riverside, CA). Although most of the markets are large or medium, a few are fairly small: 28 single-MSA markets have population of more than 1 million, eight are in the range of $0.5-1$ million, and four have fewer than 500 thousand people. Household panel data-not used in this paper-from Eau Claire, WI, and Pittsfield, MA, the two smallest markets, are also provided.

The data cover a large number of stores selling identical goods: overall, the information from 2,093 stores was collected (Kruger and Pagni 2008). About a quarter of them are drugstores, and the rest are grocery stores. The largest number of stores per market is 152 (New York, NY). Each market except Eau Claire, WI, supplied information from at least 10 stores, and 39 markets provided information from 20 or more stores. In accordance with contractual agreements, the data provider masks retailer names; a store key is then mapped to an anonymous retailer key classified as a grocery or drug store, providing information that can be used to compute price dispersion within and between chains, as well as between the types of stores. ${ }^{10}$ The dataset also provides stores' annualized sales across all categories and nonprescription drugs, which can be used as a measure of store size.

The data cover products at the UPC level in 31 consumer categories from grocery and drug stores: 14 of them cover food, three beverages, and 14 personal-care items (such as shampoo or toothbrush), household supplies (cleaners, detergent), photo supplies, or cigarettes. ${ }^{11}$ Each UPC is mapped to a particular brand, vendor, and parent company, with a detailed description of each item, including attributes such as size/volume, content, form, or style (attributes vary by category). All private-label UPCs are masked.

The dataset reports transactions at a weekly frequency. Some datasets studied in the past (the BLS Research data among others) report observations at a monthly frequency, making it harder to distinguish between cross-store price dispersion at a point in time and the monthly variation of prices within stores. In addition, using data at a weekly frequency allows me to assess the effect of aggregation on the estimates

\footnotetext{
${ }^{8}$ Eichenbaum et al. (2014) criticize this approach, because artificial price changes stemming from measurement error (rather than store actions) break price spells, leading to downward bias in the estimates of spell duration. However, small price changes (whether genuine or not) do not have a material effect on the measurement of price dispersion.

${ }^{9}$ Of 50 markets, about 40 correspond to the MSA level, one (Raleigh/Durham, NC) combines two MSAs in the same Combined Statistical Area (CSA), five markets combine two MSAs in different CSAs of the same state (for example, Buffalo/Rochester, NY), two (Mississippi and South Carolina) are at the state level, and two represent geographic areas in more than one state (New England and West Texas/New Mexico). A complete list of geographic markets can be found in Appendix A.

${ }^{10}$ Due to the complexity of mergers and acquisitions (M\&A) in the retail sector, sometimes one store belongs to more than one chain during the same year. Since a store pricing strategy might change as a result of M\&A (as reflected in clearance sales, opening discounts, loyalty programs), I drop stores that change ownership from the computation of cross-chain price dispersion.

${ }^{11} \mathrm{~A}$ complete list of the categories can be found in Appendix A.
} 
of price dispersion and its properties.

\subsection{Measurement}

Although there exist different measures of price dispersion, the coefficient of variation (CV), defined as a ratio of the standard deviation to the mean, and the standard deviation of log prices are the two used most widely in the literature (Baye, Morgan, and Scholten 2010). ${ }^{12}$ While the standard deviation, computed in levels, is not invariant to linear transformation, the standard deviation of logs and the CV are, describing a distribution's second moment in relative, rather than absolute, terms. As the two measures are asymptotically equivalent, in the main text I focus on the former. ${ }^{13}$ This benchmark measure of price dispersion has a number of useful properties. First, it is a component of the welfare function in standard macro models (Woodford 2003). Second, unlike percentile-based measures such as the interquartile range or gap, it incorporates prices from all stores, instead of looking at the price difference between two stores with a specific ranking.

To describe how price dispersion is measured, let $T S_{\text {ismt }}$ and $T Q_{\text {ismt }}$ be total sales and quantities, respectively, for good $i$, store $s$, market $m$, and week $t$. Then, the unit value price index is computed as $P_{i s m t}=T S_{i s m t} / T Q_{i s m t}$, and the weekly measure of price dispersion $\left(\sigma_{i m t}^{\text {week }}\right)$ as the standard deviation of $\log P_{\text {ismt }}$ over stores. Next, this measure is aggregated to a monthly frequency by averaging over weeks, which is done for two main reasons: (1) to remove high-frequency variation resulting from transitory factors and missing values; and (2) to obtain a dispersion series at the same frequency as aggregate variables such as inflation, unemployment, or labor force participation. Once I have a monthly measure of dispersion for a given product $\left(\sigma_{\text {imt }}^{\text {month }}\right)$, I aggregate it over products. I use a product's annual $(\tau)$ share of total sales within a given market as weights: $\sigma_{m t}=\sum_{i} \omega_{i m t} \sigma_{i m t}^{\text {month }}$, where $\omega_{i m t}=\sum_{s} T S_{i s m \tau} /$ $\sum_{i, s} T S_{i s m \tau} \cdot{ }^{14,15}$

As a robustness check, I also consider alternative ways to compute and aggregate price dispersion. First, I use the quantity-weighted standard deviation of log prices. This approach is inferior to the benchmark for two reasons: (1) In theory, macro models document the relationship between the raw standard deviation of prices and inflation. (2) Empirically, this approach makes the resulting measure sensitive to a large player's behavior. ${ }^{16}$ However, the results obtained for the alternative measures are close to the benchmark. ${ }^{17}$

Second, to tackle a missing-values problem, the data are aggregated to a monthly frequency before price dispersion is computed. (First, I compute $P_{i s m t}=\sum T S_{i s m t} / \sum T Q_{i s m t}$, where sums are over weeks within the same month. Then, I take the standard deviation of $\log P_{i s m t}$. ) This approach is less viable because, ideally, we need to observe prices across stores at exactly the same point in time. If two stores

\footnotetext{
${ }^{12}$ The range (max-min spread) and interquartile range (75th-25th percentile spread) are also widely used. In the industrialorganization and search literatures, alternative measures have been developed, including the value of information (the difference between the mean and the minimum price) and the gap (the difference between the two lowest prices). For an overview, see Baye, Morgan, and Scholten (2010).

${ }^{13}$ The standard deviation of log prices allows removing seller fixed effects and therefore is chosen as a preferred measure.

${ }^{14}$ In the regression analysis, I aggregate the data to the market-category level.

${ }^{15}$ Alternatively, as a robustness check, I use weights common across the markets, $\omega_{i t}=\sum_{s, m} T S_{i s m \tau} / \sum_{i, s, m} T S_{i s m \tau}$.

${ }^{16}$ For example, large fluctuations in dispersion may be entirely due to a big retailer such as Walmart (not in the data) having massive sales.

${ }^{17}$ The results based on the quantity-weighted measure of dispersion were circulated in the previous draft of this paper.
} 
always have identical prices, but we observe one store at the beginning of the month and the other at the end, such aggregation will produce spurious dispersion. However, if we observe one store on the last day of week 1 and the other on the first day of week 2, it increases the number of observations.

Third, since the dataset contains a sample, rather than a universe, of stores at the market-UPC level, I experiment with the minimum number of stores required to estimate price dispersion. Requiring broader store coverage improves estimation precision at the cost of eliminating UPCs, and even entire markets. For the baseline estimates, I use the entire dataset (that is, any UPC with at least two stores in the market). Additionally, I produce dispersion estimates for observations with at least 10 or 20 stores in a given week. The level of price dispersion slightly rises with the number of stores, since markets with more stores are usually spread out and tend to have larger price dispersion (among other things, searching for best prices in a large metro area is more costly than in a small town). However, this difference is small, and does not materially affect the main results.

Posted and Regular Prices Temporary price reductions, or "sales," last for a short period of time, and are often thought to have a limited effect on aggregate-price properties (Kehoe and Midrigan 2014). Pricestickiness studies point out that regular prices (excluding sales) are much stickier than posted ones. ${ }^{18}$ Since the dataset used in this paper contains about 20 percent of products on sale during a given week, and the average size of sales is 25 percent (Coibion, Gorodnichenko, and Hong 2015), without perfect synchronization of sales, one should expect price dispersion to be significantly larger for posted prices than for regular prices.

The identification of sales requires controlling for their duration, which can vary from one week to a few months, and choosing a specific algorithm. To illustrate the problem, consider the price spell $\{\$ 5$, $\$ 5$, $\$ 2$, n.a., $\$ 2, \$ 5$, with "n.a." indicating missing values. It is easy to guess that, in this example, the regular price is $\$ 5$ and the sale price is $\$ 2 .{ }^{19}$ There are three ways, however, to assign values for the sale indicator: $(i)$ the most restrictive procedure requires observing consecutive observations, implying the sales indicator series $\{0,0$, n.a., n.a., n.a., 0$\}$; (ii) the intermediate case requires dropping missing values, which thereby do not break the spell, $\{0,0,1$, n.a., 1, 0\}; and (iii) the least restrictive way replaces missing values with the imputed value of $\$ 2,\{0,0,1,1,1,0\}$.

The IRI dataset supplies a temporary price reduction flag, which is based on the firm's proprietary algorithm. The flag indicates a temporary price reduction of 5 percent or more. Previous studies that used this flag (Coibion, Gorodnichenko, and Hong 2015) report that the properties of regular prices identified with its help are similar to those when other popular sales filters were used. ${ }^{20}$ Based on that, I use the IRI sales flag to identify regular prices.

\footnotetext{
${ }^{18}$ Nakamura and Steinsson (2008), using the BLS Research data, show that regular prices change on average every 8-11 months, while posted prices remain unchanged for about 3-5 months.

${ }^{19}$ Here, I implicitly assume that sales can last for at least three weeks (therefore, $\$ 2$ is not another regular price), and that the price stayed at $\$ 5$ for a considerable period before and after this spell (to abstract from truncation).

${ }^{20}$ Since price dispersion estimates are not based on the identification of price spells, they are less sensitive to the choice of sales filter than, for example, estimates of the frequency of regular price changes.
} 
Table 1. Average Standard Deviation of Log Price in Market and Week, log points

\begin{tabular}{|c|c|c|c|c|c|c|c|c|c|c|}
\hline & \multicolumn{3}{|c|}{ Overall } & \multicolumn{2}{|c|}{ Store Type } & \multicolumn{3}{|c|}{ Category } & \multicolumn{2}{|c|}{ Stockpiling } \\
\hline & $\begin{array}{c}\text { Across } \\
\text { stores } \\
(1)\end{array}$ & $\begin{array}{c}\text { Across } \\
\text { chains } \\
\text { (2) }\end{array}$ & $\begin{array}{l}\text { Net of store } \\
\text { fixed effects } \\
\text { (3) }\end{array}$ & $\begin{array}{l}\text { Gro- } \\
\text { cery } \\
(4)\end{array}$ & $\begin{array}{l}\text { Drug } \\
\text { (5) }\end{array}$ & $\begin{array}{c}\text { Food } \\
(6)\end{array}$ & $\begin{array}{l}\text { Bever- } \\
\text { ages } \\
(7)\end{array}$ & $\begin{array}{c}\text { Other } \\
\text { (8) }\end{array}$ & $\begin{array}{l}\text { High } \\
\text { (9) }\end{array}$ & $\begin{array}{l}\text { Low } \\
\text { (10) }\end{array}$ \\
\hline Posted Price & 9.5 & 12.7 & 7.3 & 8.8 & 9.8 & 9.7 & 9.8 & 9.1 & 9.1 & 9.4 \\
\hline 2001-2007 & 9.7 & 12.4 & 7.4 & 9.2 & 9.5 & 10.0 & 10.2 & 9.2 & 9.1 & 9.9 \\
\hline 2008-2011 & 9.1 & 13.1 & 7.1 & 8.1 & 10.3 & 9.2 & 9.1 & 8.9 & 9.1 & 8.6 \\
\hline Regular Price & 6.6 & 9.5 & 3.2 & 6.0 & 6.0 & 6.4 & 6.6 & 6.9 & 6.9 & 6.2 \\
\hline 2001-2007 & 6.7 & 9.1 & 3.1 & 6.1 & 5.9 & 6.4 & 6.8 & 7.0 & 6.9 & 6.4 \\
\hline 2008-2011 & 6.5 & 10.3 & 3.5 & 5.6 & 6.3 & 6.3 & 6.3 & 6.8 & 6.9 & 5.9 \\
\hline
\end{tabular}

Source: Author's calculations based on the IRI data.

Notes: The table reports the average standard deviation of the log price of exactly the same products across stores (column 1 ) and across chains (column 2) in a given market and week. Column (3) reports the standard deviation of the log price net of seller fixed effects. Columns (4)-(5), (6)-(8), and (9)-(10) reproduce the results in column (1) by store type, product category, and the degree to which products can be stockpiled, respectively.

\subsection{Price Dispersion}

The average dispersion of prices is reported in column (1) of Table 1. I compute the measure separately for posted and for regular prices, as well as for the sample before and after the onset of the Great Recession. The average price dispersion during the entire sample period is $9.5 \log$ points in a week. ${ }^{21}$ Approximately one-third of this measure is due to temporary price reductions; the average price dispersion for regular prices is $6.6 \mathrm{log}$ points. This suggests that the price dispersion observed in the data is mostly due to permanent differences in prices across stores, and not due to transitory changes (sales).

I also document a decrease in the dispersion over time, of both posted and regular prices. The dispersion of posted prices goes down from 9.7 log points in 2001-2007 to 9.1 log points in 2008-2011; during the same period, a decrease in the dispersion of regular prices is smaller: from 6.7 to $6.5 \log$ points. A decrease in price dispersion found in the data is consistent with two facts. First, significant M\&A activity in the sector, which has been taking place since 2007, is likely responsible for the reduction in cross-store price dispersion, as the price is often determined at the chain, rather than store, level. Second, as many consumers saw their budget constraint tighten during the financial crisis, search intensity and store-switching contributed to the intensification of competition, leading to price convergence. ${ }^{22}$

Observed price dispersion is partly due to store- and chain-specific effects. For example, some chains choose to cater to a premium segment of customers, charging prices that are higher than their competitors'. Such amenities can be viewed as essential aspects of a product, and thereby explain the price differentials (Stigler 1961). On the other hand, even within the same chain, there is significant heterogeneity across stores related to their location and size. Price dispersion also depends on store type and product characteristics. To estimate the extent to which these factors-and not price rigidity-determine price dispersion, I compute price dispersion across chains, as well as net of store fixed effects. Then, I compare price dispersion across store types and across product types.

First, I define the "chain price" as the average log price across stores that belong to chain $c$, using individual stores' annual $(\tau)$ sales as weights: $\overline{\log }_{i c m t}=\sum_{s \in \mathscr{S}_{c}} \omega_{s m t} \log p_{\text {ismt }}$, with $\omega_{s m t}=\sum_{i} T S_{i s m \tau} /$ $\sum_{i, s \in \mathscr{S}_{c}} T S_{i s m \tau}\left(\mathscr{S}_{c}\right.$ being the set of stores that belong to chain $c$ ). Then, I proceed with aggregation as in

\footnotetext{
${ }^{21}$ This number can be interpreted as follows: if you look at the distribution of prices (of exactly the same product) over stores in a given market, a randomly picked store has a price averaging 9.5 percent higher or lower than the mean across the stores (for the same product and area).

${ }^{22}$ Appendix B plots the time-series of the average price dispersion and studies its heterogeneity across markets.
} 
the baseline case. Column (2) of Table 1 shows that price dispersion across chains is only slightly higher than across stores: 12.7 and $9.5 \mathrm{log}$ points for posted and regular prices, respectively. Interestingly, while cross-store price dispersion fell during the Great Recession, cross-chain price dispersion rose; as more consumers become price-sensitive, competition among stores intensifies. This fact may contribute to a widening divide between low- and high-price chains.

Next, I remove the store-specific component of the price by regressing the log price on product and store dummies, $\log p_{i s m t}=\alpha_{i}+\gamma_{s}+\varepsilon_{i s m t}$; and then compute the dispersion of $\varepsilon_{i s m t}$. Hence, this procedure removes the store-specific level effect—to the extent that one store consistently charges more for the same product than other stores do. This effect might be due to, among other things, a chain brand premium, the store location, size, or amenities. The store fixed effects partially explain price dispersion in the data: column (3) of Table 1 shows that these effects account for less than 25 percent of the dispersion of posted prices and less than 50 percent of that of regular prices. Similar to the benchmark measure, the net dispersion of posted prices decreases over time; and unlike the benchmark measure, the net dispersion of regular prices increases.

I proceed by comparing grocery stores and drugstores. Drugstores are known to charge higher prices for food items, arguably reflecting their convenient location, among other factors, and indicating more market power than grocery stores have. Hence, if market power is a significant determinant of price dispersion, we should observe a larger price dispersion in drugstores. Columns (4) and (5) of Table 1 show the breakdown of price dispersion by store type. The differences are rather small for posted prices, and negligible for regular prices. For example, the dispersion of regular prices is 6.0 log points, both in drug and grocery stores. If the two types are combined, it goes up to 6.6 log points. Hence, at least at the aggregate level, micro factors-to the extent that they differ between grocery stores and drugstoresaccount for only 10 percent of price dispersion.

Next, I look at product categories, which likely differ in demand elasticity. For example, some products are more perishable or bulkier than others, which makes their storage costly. To examine the importance of this channel, I compare the price dispersion of food, beverages, and other items (mostly personal care), and find no material differences in price dispersion. Columns (6)-(8) of Table 1 confirm that the aggregate level of price dispersion is similar across broad categories. The dispersion of posted prices is 9.1-9.8 log points, and that of regular prices is 6.4-6.9 log points. There is more dispersion in the posted prices of food and beverages, while the regular prices of personal care products are more dispersed than those of food and beverages, suggesting that sales are less important for nonfood categories.

Finally, I split all 31 categories into three groups, based on their suitability for stockpiling (high, medium, and low), using the classification provided by Bronnenberg, Kruger, and Mela (2008). ${ }^{23}$ Since the classification is largely ad hoc, I only compare low and high suitability categories. The results in columns (9)-(10) of Table 1 suggest that the degree of suitability for stockpiling has a very limited effect on price dispersion. Incidentally, sales explain 34 percent of price dispersion of goods with low suitability for stockpiling and 24 percent of those with high suitability.

\footnotetext{
${ }^{23}$ Products with high suitability for stockpiling, according to this classification, are small-sized and not perishable (for example, household cleaners, shampoo, toothpaste). Products that are extremely perishable (such as yogurt) or bulky (toilet tissues) are assigned low suitability. Categories such as beer or carbonated beverages are somewhere in between.
} 


\section{Empirical Analysis of Price Dispersion-Inflation Comovement}

Many prominent macro models rely on price rigidity, a feature that helps to match the average frequency, size, and synchronization of price changes in the data. Yet, different models of price stickiness are often observationally equivalent: they can simultaneously match various pricing properties, even though they imply different responses of output to shocks. Models with fixed-length price spells (Taylor 1980), a constant probability of price adjustment (Calvo 1983), fixed menu cost (Sheshinski and Weiss 1977, Akerlof and Yellen 1985, Mankiw 1985, Golosov and Lucas 2007), or stochastic menu cost (Dotsey, King, and Wolman 1999) match specific moments of the distribution of price changes, but none of them provides structural micro foundations of the source of price stickiness. Despite this limitation, sticky-price models serve as a useful aggregation tool, and are at the heart of DSGE models used by central banks for policy analysis and forecasting.

Although price-stickiness models give rise to a positive relationship between price dispersion and inflation, they vary in the degree of the comovement between these variables; thus, one can employ such comovement to distinguish between them and, in turn, generate the responses of output to shock consistent with the data. ${ }^{24}$ Next, I cover theoretical aspects of the relationship of price dispersion and inflation; then, I estimate this relationship using a model-inspired and data-driven specification.

\subsection{Theoretical Foundations of Econometric Specification}

This section motivates my empirical analysis by summarizing the testable predictions of workhorse macroeconomic models. I concentrate on three results relevant for my work: (1) In a wide class of models, price dispersion enters the per-period utility function, affecting the cost of business cycles and the tradeoff between inflation and output stability (Woodford 2003). (2) In many models, price dispersion comoves with inflation, and sometimes (for instance, in the Calvo model), there exists a closed-form relationship between the two, which permits structural estimation. ${ }^{25}$ (3) The steady-state level of inflation can influence the dispersion of prices, and in some cases (again, in the Calvo model), one can derive a simple formula that links price dispersion and inflation in the steady state. ${ }^{26}$

The relationship between price dispersion and the per-period utility function can be readily quantified. For example, in a basic New Keynesian setup (Woodford 2003, p. 396), the second-order approximation of the per-period utility function can be written as

$$
U_{t}=-\frac{\bar{Y} u_{c}}{2}\left\{(\gamma+\omega)\left(x_{t}-x^{*}\right)^{2}+\theta(1+\omega \theta) \sigma_{t}^{2}\right\}+\text { t.i.p. }+ \text { h.o.t. }
$$

\footnotetext{
${ }^{24} \mathrm{~A}$ positive relationship between price dispersion and inflation also arises in models with search frictions (Benabou 1988, 1992). However, in search models, the nature of this relationship is static (the two are only related within the same period), while in the sticky-price models and in the data, the relationship is dynamic.

${ }^{25}$ The idea that inflation drives price dispersion when pricing is state-dependent goes back to Sheshinski and Weiss (1977). In the presence of costly price adjustment, the optimal pricing is the $(S, s)$ strategy. An increase in the inflation rate leads to an increase in the size of price changes, increasing price dispersion. The model, however, abstracts from the consumer side, as without search frictions one can hardly justify nonzero demand at any price above the minimum. It assumes that the inflation rate is exogenous and deterministic, contrary to stochastic aggregate models. In a subsequent paper, Sheshinski and Weiss (1983) consider stochastic inflation and prove the certainty equivalence result.

${ }^{26}$ The equilibrium relationship is often emphasized in the search literature (Benabou 1988, 1992, 1993, Diamond 1993, Tommasi 1994). Note that without price-adjustment frictions in these models, all firms would always charge the monopoly price, thereby eliminating price dispersion in the absence of idiosyncratic shocks, known as the Diamond (1971) paradox.
} 
where $U_{t}$ is the per-period utility function, $\bar{Y}$ is steady-state output, $u_{c}$ is the marginal utility of consumption, $\gamma$ is the inverse intertemporal elasticity of substitution, $\omega$ is the elasticity of marginal cost with respect to output, $x_{t}-x^{*}$ is the deviation of the output gap from its efficient level, $\theta$ is the elasticity of substitution across goods, $\sigma_{t}^{2} \equiv \operatorname{Var}_{i} \log p_{t}(i)$ is the variance of prices across firms, t.i.p. stands for terms independent of policy, and h.o.t. stands for higher-order terms. Importantly, this approximation applies quite generally across various models of price setting.

Price dispersion has a negative effect on welfare because, in the model, it represents the distortion to optimal allocation, which arises from price rigidity. If prices are dispersed, consumers with a love for variety buy too much (too little) when the price is below (above) the average. The misallocation is amplified by the elasticity of substitution between goods $(\theta)$ and the elasticity of marginal cost with respect to output $(\omega)$. The former represents the degree of love for variety and the extent to which consumers respond to price changes. For example, when $\theta$ is high, consumers easily reallocate their expenditure toward goods whose prices have not been adjusted to inflationary shocks, amplifying the misallocation effect. The latter $(\omega)$ represents real rigidities, which amplify misallocation through marginal costs. ${ }^{27,28}$

If price setting is time-dependent as in Calvo (1983), price dispersion in Equation (1) is a function of current and past inflation, with its persistence and comovement solely determined by the degree of price rigidity (Woodford 2003, p. 399):

$$
\sigma_{t}^{2}=\alpha \sigma_{t-1}^{2}+\frac{\alpha}{1-\alpha} \pi_{t}^{2}+\text { h.o.t. }
$$

where $\alpha$ is the fraction of prices that remain unchanged, and $\pi_{t}$ is inflation. Later, I test this relationship in the data. ${ }^{29}$ It is easy to see why price stickiness implies more persistence of price dispersion. Parameter $\alpha$ in Equation (2) controls the share of prices that will not change in the next period. In the limiting case when $\alpha$ goes to one, the whole distribution stays the same, and so does price dispersion. As prices become more flexible, the relationship between current and lagged price distribution becomes weaker-perfectly flexible prices are not dispersed at all.

The comovement of price dispersion and inflation is also due to price stickiness. Consider two cases: (1) $\alpha$ is high (prices are relatively sticky), and (2) $\alpha$ is low (prices are relatively flexible). In case (1), if the economy is hit by a large nominal shock, few firms will be able to adjust their prices. Those few firms, however, will adjust proportionally to the size of the shock. Since most prices remain unchanged, the response of price dispersion is stronger than the response of inflation-due to the size of changes made by adjusters-implying a large slope. In case (2), when prices are relatively flexible, many firms will adjust in response to the shock, with the response of inflation stronger than the response of price dispersion (small slope). Remarkably, the direction of the shock is irrelevant; deflationary and inflationary shocks affect price dispersion in the same way. This intuition applies generally to models with time-dependent pricing: volatile inflation is associated with more price dispersion. In contrast, models with state-dependent pricing can produce a positive or negative relationship of price dispersion and inflation, and the outcome depends

\footnotetext{
${ }^{27}$ See Ball and Romer (1990) for the analysis of real rigidities and their connection to nominal rigidities.

${ }^{28}$ Nakamura and Steinsson (2013) point out that the dispersion of prices across stores implies that the goods produced with the same marginal costs are purchased at different prices, thereby violating the equality of marginal revenues and marginal costs, and leading to efficiency loss.

${ }^{29}$ Equation (2) is derived for the case of zero trend inflation. With positive trend inflation, the right-hand side should also contain the level of inflation.
} 
on the specifics of the model, as well as on the history and magnitude of shocks hitting the economy. ${ }^{30}$

In the case of positive trend inflation, price dispersion is related to inflation in the steady state, too. With no price indexation, in the steady state of the Calvo model the relationship is the following:

$$
\bar{\sigma}^{2}=\frac{\alpha}{(1-\alpha)^{2}} \bar{\pi}^{2}+\text { h.o.t. }
$$

where $\bar{x}$ is a steady-state value of variable $x, x \in\{\sigma, \pi\}$. The link between price stickiness and price dispersion is again intuitive: In the Calvo model, firms are symmetric monopolistic competitors, whose optimal markup depends only on demand elasticity, which in turn is captured by the elasticity of substitution between goods. If prices are flexible and marginal costs are the same across firms, they will charge the same price, implying no price dispersion in equilibrium. If prices are sticky, however, some firms will not be able to adjust the price, leading to equilibrium price dispersion. Similar to the case of price-dispersion dynamics, this result applies to models with time-dependent pricing, but the relationship is ambiguous in models with state-dependent pricing.

\subsection{Empirical Strategy and Results}

Estimating the comovement of inflation and price dispersion at the aggregate level runs into several problems. First, in 2001-2011, there was not enough variation in aggregate inflation, as it was predominantly low and stable. Second, with 132 monthly observations at hand, it is virtually impossible to account appropriately for the correlation structure of residuals, to control for lags, or to split the sample around the beginning of the Great Recession.

Instead, I resort to using disaggregated data at the market-category level, and then I validate the results by looking at the aggregate data (Appendix C). Using inflation and price dispersion in 50 markets and 31 product categories (1550 panels overall) allows me to easily overcome the problems described above. One justification for this strategy is theoretical: multisector models with sticky prices (Carvalho 2006) give rise to a relationship between sectoral inflation and price dispersion that is similar to the one between the aggregate variables. Another justification is empirical: the comovement coefficients derived from the regressions based on aggregate data-although estimated imprecisely and with a limited number of controls-are qualitatively similar.

To measure inflation at the market and product category level, I construct disaggregated inflation rates, using the same data (and method) as before. ${ }^{31}$ Specifically, I compute the log difference of the average monthly price for a given good and store, $\Delta p_{i s m t}=\log P_{i s m, t}-\log P_{i s m, t-1}$, and then aggregate it over stores and products to the market-category level: $\pi_{m c t}=\sum_{s, i} \omega_{i s m t} \Delta p_{i s m t}$, with $\omega_{i s m t}=T S_{i s m \tau} / \sum_{s, i} T S_{i s m \tau}$ being the share of annual $(\tau)$ sales of product $i$, store $s$, in total sales in market $m$, category $c$. $^{32}$ This approach corresponds to the enhanced Törnqvist index, with weights based on all months in a year, and not just two adjacent months. ${ }^{33}$ For ease of interpretation, I use annualized rates.

\footnotetext{
${ }^{30}$ Later, I show that a reasonably calibrated DSGE model with state-dependent pricing gives rise to a positive comovement of inflation and price dispersion, with a much smaller slope than in a similar model with time-dependent pricing.

${ }^{31}$ Appendix D provides more detail on disaggregated inflation rates.

${ }^{32}$ These weights treat the same good in different stores as different products. In Appendix E, I consider multiplicative weights instead, and show that this choice does not drive the results.

${ }^{33}$ In sticky-price models, the relationship between inflation and price dispersion arises from individual firms' decisions to adjust their prices, and not from their view of inflation as a change in the aggregate price level. Hence, to preserve comparability with
} 
Structural Specification The Calvo model extended to the case of positive trend inflation observed in the data gives rise to the following structural specification:

$$
\sigma_{m c, t}^{2}=\alpha \sigma_{m c, t-1}^{2}+\beta_{1} \pi_{m c, t}^{2}-\beta_{2} \pi_{m c, t}+\gamma_{m c}+\tau_{t}+\varepsilon_{m c, t}
$$

where $\sigma_{m c, t}$ is price dispersion across stores in market $m$, category $c$, and month $t$ (see Section 2.2 for details), $\pi_{m c, t}$ is the corresponding disaggregated inflation rate (see Appendix D), $\gamma_{m c}$ and $\tau_{t}$ are marketcategory and time fixed effects, respectively, and $\varepsilon_{m c, t}$ is the error term. ${ }^{34}$ Standard errors are computed as in Driscoll and Kraay (1998), to account for serial correlation of up to 12 months and correlation across groups. ${ }^{35}$ Both variables are seasonally adjusted using the X12-ARIMA routine, developed by the U.S. Census and applied to government-issued data. ${ }^{36}$ To alleviate extra smoothness that arises from seasonal adjustment (which may affect the estimation of $\alpha$ ), as a measure of lag dispersion, I use the value in the same month of the previous year. ${ }^{37}$

To check whether the theory is consistent with the data, I verify three conditions: (1) the slope of the squared inflation rate is positive $\left(\beta_{1}>0\right)$; (2) the slope of the inflation level is negative $\left(-\beta_{2}<0\right)$; and (3) price dispersion increases with inflation around the steady state:

$$
2 \beta_{1} \bar{\pi}-\beta_{2}>0
$$

These three conditions, however, hold simultaneously neither for posted nor for regular prices. For posted prices (Table 2, Panel A, columns 1-3), the comovement of price dispersion and inflation is negative around the steady state, thereby violating condition (3). For regular prices (Table 2, Panel B, columns 13 ), condition (3) holds, but the other two conditions are violated: the slope of the inflation level is positive, and the slope of the squared term is negative. (This result holds with and without market-category and time fixed effects.) The degree of price-dispersion persistence, measured by $\alpha$ in Equation (4), also refutes the structural specification. In the specification with fixed effects, the benchmark estimate of $\alpha$ is 0.54 , implying that the corresponding monthly frequency of price changes $(1-\alpha)$ is 0.46 . However, in the data, the monthly frequency of price changes is about $0.24 .^{38}$ The inability of the structural form to match the data, together with the estimation difficulties associated with the form itself (lagged dependent variable and right-hand side polynomial, which aggravate multicollinearity and assign more weight to outliers) call for a more flexible, data-driven specification.

theoretical models, it is essential to aggregate price dispersion and inflation in a similar way.

${ }^{34}$ The problem of the lagged dependent variable can be solved by iterating backward. Table F1 in Appendix F shows that this approach leads to similar results.

${ }^{35}$ Driscoll and Kraay (1998) standard errors are known to be conservative. Allowing for 12 months of serial correlation is very generous, given that there are only 11 years of observations in the data.

${ }^{36}$ Comparing regression outcomes from the X12-ARIMA seasonally adjusted data, unadjusted series, and those smoothed through a parsimonious MA(12) filter suggests that seasonal adjustment is not particularly relevant for qualitative results.

${ }^{37}$ The MA(12) filter implies the following transformation: $\Delta \tilde{x}_{t}=x_{t}-x_{t-12}$, where $x_{t}$ is an original variable, and $\tilde{x}_{t}$ is the MA(12) smoothed one. Therefore, a change in $\tilde{x}$ can be interpreted as a change relative to the same month in the previous year, implying that $\Delta \tilde{x}_{t-12}$ should be used as a lag value. The X12-ARIMA and MA(12) regressions give similar results, justifying my choice of the lag measure for the main specification. Importantly, this does not have any qualitative effect on the results, and could only be crucial if the main point of interest were estimating $\alpha$.

${ }^{38}$ Since as a lag measure, I use the value of price dispersion in the same month of the previous year, I can also compare $1-\alpha$ to the annual frequency of price changes. The monthly frequency (0.24) implies that the annual frequency is 0.96 , which corresponds to $\alpha=0.04$ (far from 0.54 obtained in the regression). When instead, I use price dispersion in the previous month, the estimated $\alpha$ is very close to 1 , which is again far from the monthly frequency $(0.24)$. 


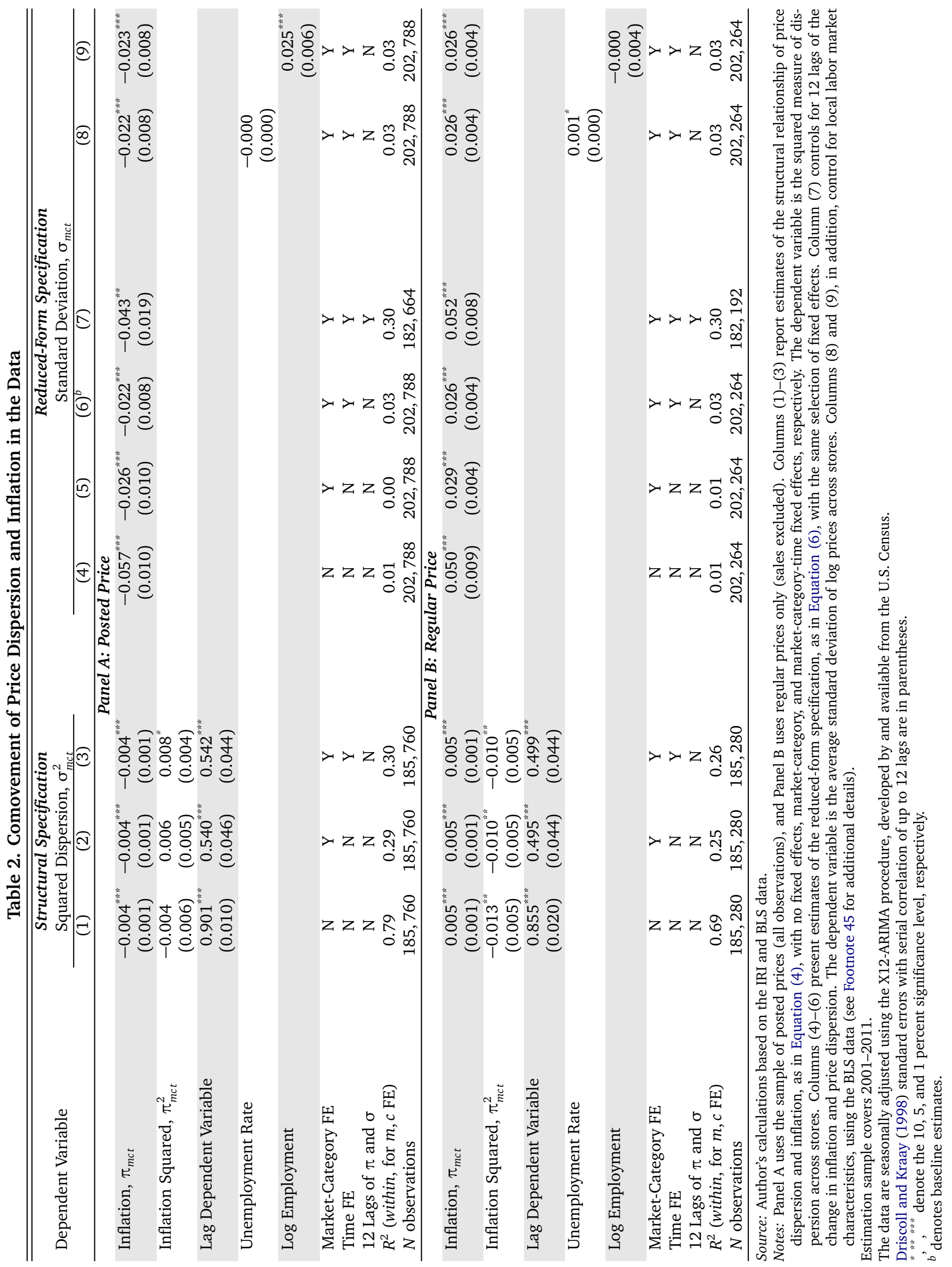


Reduced-Form Specification Since the Calvo-driven specification fails to match the data, I propose a simple, flexible specification that allows for a straightforward measure of the comovement. The specification is based on a linear relationship between price dispersion and inflation, which is supported by the data, and allows for cross-sectional and time fixed effects, as well as for other covariates of dispersion. This specification looks as follows:

$$
\sigma_{m c t}=\beta \pi_{m c t}+\gamma_{m c}+\tau_{t}+\boldsymbol{\delta}^{\prime} \boldsymbol{X}_{m c t}+\varepsilon_{m c t},
$$

with $\sigma_{m c t}, \pi_{m c t}, \gamma_{m c}, \tau_{t}$, and $\varepsilon_{m c t}$ defined as in Equation (4), and $\boldsymbol{X}_{m c t}$ being a set of control variables that includes local labor market characteristics or lags of $\pi$ and $\sigma$. This specification has a number of advantages: First, the structural specification's estimates suggest that price dispersion is driven mainly by the level, and not by the squared term, of inflation: $\left|\beta_{2}\right| \gg\left|2 \beta_{1} \bar{\pi}\right|$ in Equation (4). Second, removing nonlinear terms reduces the sensitivity of results to outliers. Third, using the standard deviation, instead of the variance, improves the interpretability of the estimates-since the standard deviation of log prices can be treated as roughly the average deviation from the mean price (in percentage terms) - and makes the results directly comparable to previous studies that employed similar specifications. Finally, since the persistence term arises specifically in the Calvo model, the linear specification is more neutral, in the sense that it does not a priori favor any particular model. ${ }^{39}$

The estimates based on the reduced-form specification confirm the earlier result: the comovement of price dispersion and inflation is negative for posted prices and positive for regular prices (see columns 4-7 of Table 2 for results with no fixed effects, cross-sectional fixed effects only, cross-sectional and time fixed effects, and 12 lags of changes in inflation and price dispersion, respectively). ${ }^{40}$ The baseline specification, used later to distinguish between models, includes market-category and time fixed effects (column 6). Cross-sectional fixed effects are used to focus on the comovement of inflation and price dispersion within a given market-category, while time fixed effects control for possible time trends. ${ }^{41}$ The benchmark estimates suggest that the comovement is not only statistically significant, but also sizeable. A 1 percentage point increase in the annualized inflation rate is associated with a 0.022 log point decrease in monthly price dispersion. Once sales are excluded, a 1 percentage point increase in the annualized inflation rate corresponds to a $0.026 \log$ point increase in price dispersion. ${ }^{42}$ Hence, when the price level increases by 2 percent in a particular month, the dispersion of posted prices decreases by approximately $0.5 \log$ points (from 9.5 to $9.0 \mathrm{log}$ points, if one starts from the mean level), and the dispersion of regular prices increases by $0.6 \mathrm{log}$ points (from 6.6 to $7.2 \mathrm{log}$ points). ${ }^{43}$ Appendix G shows that the relationship

\footnotetext{
${ }^{39}$ Including the lagged dependent variable also imposes a first-order estimation problem (estimating near unit root persistence is difficult; see Phillips 1988) on a second-order question (models' predictions on the persistence of price dispersion are less conclusive than on the relationship between price dispersion and inflation). However, in one specification, I control for lags of both inflation and price dispersion.

${ }^{40}$ For the individual role of market and category fixed effects, see Table F2 in Appendix F.

${ }^{41}$ There is a lot of cross-sectional heterogeneity in price dispersion, and macro models usually produce a relationship between the aggregate variables; although in multisector models (Carvalho 2006), the relationship between sectoral variables sometimes matches the one between aggregate variables. Since the disaggregated data are mostly used to extract statistical power, it is important to control for as much heterogeneity in dispersion as possible. For completeness, Table F3 in Appendix F estimates the comovement of price dispersion and inflation between markets and categories.

${ }^{42}$ Table F4 in Appendix F studies the effects of positive and negative inflation rates separately.

${ }^{43}$ The effect of a 1 percentage point increase in the price level on price dispersion is $12 \beta$, since annualized inflation rates are used. Although a 1 percentage point increase in the monthly price level implies a formidable 12 percent annualized inflation, there is a great deal of high-frequency volatility in monthly inflation. For example, in the sample used in this paper, the price
} 
between price dispersion and inflation is dynamic, a fact that is consistent with price-stickiness models, but contrary to many search models.

Unlike the price-stickiness literature in general, previous attempts to document the relationship between price dispersion and inflation do not distinguish between regular and sale prices; in fact, many of these papers had been written before sales received a prominent place in the macro literature. The inflation-price dispersion relationship was often studied in the context of the cost of inflation, which tends to draw more attention when and where inflation is high: in the United States (Debelle and Lamont 1997), Israel (Van Hoomissen 1988, Lach and Tsiddon 1992), and Europe (Silver and Ioannidis 2001) in the 1970-1980s, or in Poland in the early 1990s (Konieczny and Skrzypacz 2005). High inflation may, among other things, disincentivize stores from temporary price reductions or result in a higher frequency of regular price changes (Gagnon 2009), which may partly explain why most of the previous studies document a positive relationship between inflation and price dispersion. However, a few exceptions, which find either a negative comovement (Reinsdorf 1994) or a lack thereof (Eden 2001, Baharad and Eden 2004), call for a search for factors that can explain the shifts in the relationship between the first and second moments of cross-sectional price distribution. ${ }^{44}$ Using data that are more extensive than those used in the previous literature, this paper identifies sales as a factor that reverts the relationship between inflation and price dispersion in a low inflation environment.

The state of local labor markets may affect search intensity and the resulting price dispersion if consumers switch between stores over the business cycle, as emphasized by Coibion, Gorodnichenko, and Hong (2015). Since the unemployed arguably incur smaller search costs, as they have more time-which is also less productive-to look for best prices, distress to local labor market conditions may lead to an increase in search intensity. To account for this effect, I control (separately) for two measures of the state of local labor markets: the local unemployment rate and total employment. The former accounts for the flow between employment and unemployment, while the latter also includes the flow out of the labor force, which is particularly important during the Great Recession, and migration. The data on local labor market characteristics come from the Bureau of Labor Statistics (BLS). ${ }^{45}$ Controlling for the state of local labor markets does not quantitatively change the estimates of the comovement of price dispersion and inflation. Column (8) of Table 2 shows the estimates for the case when the local unemployment rate is controlled for, while column (9) controls for log employment. I include the two measures separately, as there is a sufficient degree of correlation between them. The slope of the local unemployment rate is insignificant for posted prices, and significant but quantitatively small for regular prices. The slope of log employment is positive for posted prices; as employment increases, people search for better prices less, leading to a larger price dispersion.

level of a market-category changes by more than 1.25 percentage points (or, 15 percent, annualized) more than 20 percent of the time. This might be partly due to measurement error, a known issue of disaggregated price indexes.

${ }^{44}$ Choi (2010), using U.S. and Japanese data from the 1970s to mid-2000s, finds a positive relationship between inflation and price dispersion in a high-inflation environment, and a nonlinear one (U-shaped around a positive threshold) during the Great Moderation. Grier and Perry (1996) also show that a positive relationship, identified in the previous literature, often comes from episodes of volatile inflation.

${ }^{45}$ The data on local unemployment rates are from the Local Area Unemployment Statistics (LAUS); those on total nonfarm employment are from the Current Employment Statistics (CES). Both series are seasonally adjusted. Each observation is measured at the corresponding MSA level, when applicable. For Mississippi and South Carolina, the data are at the state level; for New England at the corresponding U.S. Census division level (NRD810000 "New England"); for West Texas/New Mexico, I combine New Mexico at the state level with seven MSAs in West Texas: Abilene, Amarillo, El Paso, Lubbock, Midland, Odessa, and San 
Table 3. Stability and Source of Comovement

\begin{tabular}{|c|c|c|c|c|c|c|}
\hline & \multicolumn{3}{|c|}{ Panel A: Great Recession } & \multicolumn{3}{|c|}{ Panel B: Chain and Store Effects } \\
\hline & $\begin{array}{c}2001- \\
2011^{b} \\
(1)\end{array}$ & $\begin{array}{c}2001- \\
2007 \\
(2)\end{array}$ & $\begin{array}{c}2008- \\
2011 \\
(3)\end{array}$ & $\begin{array}{c}\text { Across } \\
\text { Stores }^{b} \\
\text { (4) }\end{array}$ & $\begin{array}{c}\text { Across } \\
\text { Chains } \\
\text { (5) }\end{array}$ & $\begin{array}{l}\text { Net Seller } \\
\text { Effect } \\
(6)\end{array}$ \\
\hline Posted Price & $\begin{array}{c}-0.022^{* * * * k} \\
(0.006)\end{array}$ & $\begin{array}{c}-0.029^{* k \cdots k} \\
(0.006)\end{array}$ & $\begin{array}{c}-0.006 \\
(0.004)\end{array}$ & $\begin{array}{c}-0.022^{k * 2 k} \\
(0.006)\end{array}$ & $\begin{array}{c}-0.027^{k+\cdots k} \\
(0.006)\end{array}$ & $\begin{array}{c}-0.012^{k *} \\
(0.006)\end{array}$ \\
\hline Regular Price & $\begin{array}{l}0.026^{* * * *} \\
(0.004)\end{array}$ & $\begin{array}{l}0.020^{* * * *} \\
(0.003)\end{array}$ & $\begin{array}{c}0.022^{* * * *} \\
(0.006)\end{array}$ & $\begin{array}{l}0.026^{* * * *} \\
(0.004)\end{array}$ & $\begin{array}{l}0.024^{* * * *} \\
(0.008)\end{array}$ & $\begin{array}{l}0.059^{* * * * *} \\
(0.004)\end{array}$ \\
\hline
\end{tabular}

Source: Author's calculations based on the IRI data.

Notes: Panel A reproduces the baseline estimates of the comovement (column 1) obtained from the sample period before (column 2) and after (column 3) the beginning of the Great Recession. Panel B does the same for different measures of price dispersion: column (5) uses the crosschain measure, and column (6) removes the seller fixed effects (see Section 2.3 for more detail). The estimation sample in Panel B covers 20012011. The data are seasonally adjusted using the X12-ARIMA procedure from the U.S. Census. Driscoll and Kraay (1998) standard errors with serial correlation of up to 12 lags are in parentheses.

,***;** denote the 10,5 , and 1 percent significance level, respectively; ${ }^{b}$ denotes baseline estimates.

Next, I split the sample around the beginning of the Great Recession to verify whether the overall change in economic conditions (and, in particular, a drop in inflation) affects the degree of the comovement of price dispersion and inflation. The data reveal very different effects of the recession on posted and regular prices (Panel A of Table 3). In the case of regular prices, there is no material change in the comovement coefficient around 2008. At the same time, I find a significant drop (in absolute value) in the comovement coefficient of posted prices: from -0.029 in 2001-2007 to -0.006 in 2008-2011. One potential explanation is that consumers increase their intensity of search for sales. If so, sellers will find it more difficult to sustain regular and sale prices simultaneously, moving the two comovement measures closer to each other. However, a more trivial explanation may be that a longer time-series is needed to estimate the comovement of posted prices with higher precision. Since posted prices are much more volatile than regular prices, it is more difficult to distinguish between the idiosyncratic volatility of sales and purely seasonal volatility. ${ }^{46}$

Finally, I consider alternative measures of price dispersion. Theory provides little guidance as to whether price dispersion should be measured across stores or across chains, or how to deal with storespecific effects. However, distinguishing between price dispersion across stores and across chains is not particularly important, since the comovement coefficients differ only slightly (compare columns 1 and 2 in Panel B of Table 3). Removing seller-specific effects from prices, as described in Section 2.3, has a quantitatively bigger effect on the coefficients: the comovement of posted prices becomes less negative and the comovement of regular prices turns more positive (Table 3, Panel B, column 3)-both remain statistically different from zero. This discrepancy, however, does not have a qualitative effect on the ability of tested models to match the data.

To summarize, the empirical part of this paper reveals robust comovement of price dispersion and inflation, negative in posted prices and positive in regular prices. These results hold across a range of econometric specifications, sample periods, aggregation procedures, and dispersion measures. The nature of the relationship between inflation and price dispersion is dynamic - that is, inflation innovations tend to have a persistent effect on price dispersion. Aggregate variables other than inflation do not seem to have a strong association with price dispersion. The remainder of the paper studies whether these

\footnotetext{
Angelo.

${ }^{46}$ Other potential explanations such as a larger measurement error or the effect of M\&A activities are less likely to be at play, since they should affect posted and regular prices in a similar way.
} 
facts are consistent with workhorse macro models that policymakers widely rely on and whether the new comovement estimates produced in this paper can help to distinguish between them.

\section{Models with Testable Predictions}

Despite the vast evidence of incomplete nominal adjustment, there is no agreement on the mechanism generating price rigidity in the macro literature. The leading explanations are based on one of the two competing assumptions: (1) price setting is time-dependent-that is, firms change their prices deterministically every $n$th period (Taylor 1980) or stochastically with a given probability $p$ every period (Calvo 1983); or (2) price setting is state-dependent-due to costly price adjustment, firms react to changes in economic conditions only when the benefit of doing so exceeds the cost. The latter class of models originally evolved from the notion of a fixed menu cost (Sheshinski and Weiss 1977, 1983); however, recent modifications that allow for stochastic menu costs or multiproduct firms with a fixed cost of changing the entire price line have also gained recognition in the literature. ${ }^{47}$ Although time-dependent and state-dependent models, in general, can match the frequency of price changes in the data, they make very different predictions about the response of output to nominal shocks: due to a strong selection effect, output response in state-dependent models is smaller and shorter than in time-dependent models. Hence, looking at other testable predictions should help to distinguish between the two, and shed new light on the effectiveness of monetary policy and nominal shocks.

In this section, I compute the model-generated comovement of inflation and price dispersion, defined as in the previous section, and then compare the simulated data with the actual data. To make sure that the price-setting process is the only difference between the compared models, I build the analysis around the smoothly state-dependent pricing (SSDP) model of Costain and Nakov (2011a,b). The SSDP model allows for both time-dependent and state-dependent frictions; it also contains the Calvo (1983) and fixed menu cost (FMC) models as special cases, and can be trivially extended to the stochastic menu cost (SMC) model of Dotsey, King, and Wolman (1999). Specifically, I address the following questions: (1) Is the comovement of price dispersion and inflation in the data described better by a time- or a statedependent process? (2) Can a hybrid model that allows for both frictions-and that is calibrated to match the frequency and the distribution of the sizes of price change-also match the comovement of price dispersion and inflation in the data? (3) How should the relative importance of the two frictions be altered to match the comovement, and what does this imply for the model's ability to match other pricing moments? The answer to the first two questions is no: standard models of price setting, without sales, cannot reproduce the comovement of price dispersion and inflation in the data. As the baseline SSDP model is quantitatively similar to the Calvo (1983) model, in order to match the comovement, pricing should be more state-dependent, implying a counterfactually low mass of small price changes. I then show that introducing sales into the Calvo model can be an effective way to increase price flexibilitythereby matching the comovement-while preserving a relatively large share of small price changes.

I proceed as follows: I first lay out the basics of the SSDP model and describe how it encompasses a rudimentary time- and state-dependent case. Then, I compare the ability of different versions of this

\footnotetext{
${ }^{47}$ Anderson et al. (2013) put forward the idea of "sticky plans": firms set a contingency plan of prices, rather than a single price.
} 
model to match the comovement of price dispersion and inflation in the data. Finally, I compare models without sales with a model with sales. In particular, I run a horse race of the models with a fixed price-adjustment probability (Calvo 1983), fixed menu cost (Golosov and Lucas 2007, henceforth, GL), both frictions (Costain and Nakov 2011a,b, henceforth, CN), and sales (Guimaraes and Sheedy 2011, henceforth, GS). This section describes the models, and the next section presents the results.

\subsection{Smoothly State-Dependent Pricing as Generic Framework}

First, I describe the SSDP model and its main elements; for a detailed description, solution methods, and implications for other moments of price setting, see the original work of Costain and Nakov (2011a,b). SSDP is a hybrid model that allows for a mix of time- and state-dependent frictions and that matches the frequency and the distribution of the sizes of price change in the data-two standard success criteria of a pricing model-and features a variety of driving shocks, including idiosyncratic productivity, total factor productivity, and monetary shocks. The monetary shocks stem either from a monetary-policy rule à la Taylor or from balanced money growth à la Friedman (which is also a building block of Golosov and Lucas 2007). The key implication of the model is that in order to match the distribution of the sizes of price change in the data, the degree of state dependence should be low; therefore, unlike in Golosov and Lucas (2007), nominal shocks have a nontrivial effect on output. ${ }^{48}$

A key assumption of the SSDP model holds that the probability of price adjustment rises with the gains of doing so. However, there is no actual cost to pay, and the probability of price adjustment is determined by an exogenous time-dependent friction. Such a mechanism can be rationalized by a stochastic menu cost (SMC), as in Dotsey, King, and Wolman (1999), or bounded rationality, as in Akerlof and Yellen (1985). In the SMC case, the parametric function of the probability of price adjustment comes from the distribution of menu costs; while in the bounded rationality case, it represents the error of evaluating the state, since errors are more likely to occur when they are not costly. In the limit, the model nests the Calvo (1983) model and the FMC setup of Golosov and Lucas (2007), and can be further extended to the Dotsey, King, and Wolman (1999) case. ${ }^{49}$ Specifically, the probability of price adjustment $(\lambda)$ is a function of the loss from inaction $(L)$ :

$$
\lambda(L)=\frac{\bar{\lambda}}{\bar{\lambda}+(1-\bar{\lambda})\left(\frac{\alpha}{L}\right)^{\xi}} .
$$

This functional form has two advantages. First, it matches the frequency and distribution of the sizes of price change in the data much closer than the Calvo and FMC models do. Second, it nests the two as a limiting case: (1) $\lambda(L) \rightarrow \bar{\lambda}$ when $\xi \rightarrow 0$, that is, it converges to Calvo (1983), and (2) $\lambda(L)=\mathbb{1}\{L>\alpha\}$ when $\xi \rightarrow \infty$, as in the FMC model. Hence, $\bar{\lambda}$ captures time-dependent frictions, $\alpha$ captures statedependent frictions (menu cost), and $\xi$ controls the relative importance of the two. Conditional on the overall state, the loss from inaction is $L\left(P_{i, t}\right)=\max _{P} V(P)-V\left(P_{i, t}\right)$.

The baseline model features monopolistically competitive firms with price-adjustment frictions and

\footnotetext{
${ }^{48}$ Another way to achieve monetary non-neutrality in models with state-dependent pricing is to introduce multiproduct firms with a menu cost of changing all prices simultaneously, as in Midrigan (2011) and Alvarez and Lippi (2014). In the SSDP and multiproduct-firm models, generating a large mass of small price changes observed in the data is key for this result.

${ }^{49}$ Costain and Nakov (2011a) point out that the SSDP model produces responses to shocks that are numerically close to those in the Dotsey, King, and Wolman (1999) and Woodford (2009) models.
} 
persistent idiosyncratic productivity. There are two variations of monetary policy: the Taylor rule and constant money growth. The Taylor rule is used as a baseline, while the Friedman rule allows the comparison to Golosov and Lucas (2007). There are three types of driving shocks in the economy: monetary shocks modeled as innovations to the Taylor or Friedman rule, aggregate productivity shocks (TFP), and idiosyncratic productivity shocks. ${ }^{50}$ Price dispersion arises from heterogeneity in costs, the frictions in price adjustment, and consumers' love of variety.

Households A representative household maximizes the discounted value of its per-period utility stream, $U_{t}=\sum_{\tau=t}^{\infty} \beta^{\tau-t} u_{\tau}$, with

$$
u_{t}=\frac{C_{t}^{1-\gamma}}{1-\gamma}-\chi N_{t}+v \log \frac{M_{t}}{P_{t}}
$$

where $\gamma$ is the inverse intertemporal elasticity of substitution, $\chi$ controls the elasticity of labor supply, and $v$ is the real-money-balances parameter. The household consumes a variety of goods aggregated by the Dixit-Stiglitz function, $C_{t}=\left(\int_{0}^{1} C_{i, t}^{(\varepsilon-1) / \varepsilon} d i\right)^{\varepsilon /(\varepsilon-1)}$, with the elasticity of substitution $\varepsilon$. The budget constraint is given by

$$
\int_{0}^{1} P_{i, t} C_{i, t} d i+M_{t}+\frac{B_{t}}{1+r_{t}}=W_{t} N_{t}+M_{t-1}+T_{t}+B_{t-1} .
$$

The nominal bonds $\left(B_{t}\right)$ are in zero supply. Seigniorage and firms' profits are returned to the household.

Firms Firms are monopolistic competitors whose per-period profit function is given by

$$
\Pi_{i, t}=P_{i, t} Y_{i, t}-W_{t} Y_{i, t}
$$

The firms' production function is linear in labor, $Y_{i, t}=A_{i, t} N_{i, t}$. Idiosyncratic productivity follows an AR(1) process in logs:

$$
\log A_{i, t}=\rho_{A} \log A_{i, t-1}+\varepsilon_{i, t}^{A} .
$$

The demand function is given by $Y_{i, t}=C_{t}\left(P_{i, t} / P_{t}\right)^{-\varepsilon}$, where $P_{t}=\left(\int_{0}^{1} P_{i, t}^{1-\varepsilon} d i\right)^{1 /(1-\varepsilon)}$ is the Dixit-Stiglitz price index.

Monetary Policy Following Costain and Nakov's (2011a) approach, I consider two alternative assumptions about the conduct of monetary policy: (1) the Taylor rule of the form

$$
\check{R}_{t}=\varphi_{R} \check{R}_{t-1}+\left(1-\varphi_{R}\right)\left(\varphi_{\pi} \check{\pi}_{t}+\varphi_{C} \check{C}_{t}\right)-z_{t},
$$

where $\check{X}=\log X-\log \bar{X}$ is the $\log$ deviation from the steady state; and (2) the balanced money-supply growth perturbed by an AR(1) shock:

$$
\frac{M_{t}}{M_{t-1}}=\mu \exp z_{t}
$$

\footnotetext{
${ }^{50}$ Idiosyncratic productivity shocks do not have an effect on aggregate fluctuations, due to the law of large numbers.
} 


$$
z_{t}=\varphi_{M} z_{t-1}+\varepsilon_{t}^{M}
$$

The second approach (hereafter referred to as Money Growth) is only used for comparison purposes (with Golosov and Lucas 2007).

Equilibrium Dynamics The household first-order condition produces a standard Euler equation,

$$
\mathbb{E}_{t}\left[\frac{P_{t+1} C_{t+1}^{\gamma}}{P_{t} C_{t}^{\gamma}}\right]=\beta\left(1+r_{t}\right),
$$

and two intratemporal conditions,

$$
\begin{aligned}
\chi C_{t}^{\gamma} & =\frac{W_{t}}{P_{t}}, \\
\frac{r_{t}}{1+r_{t}} v^{-1} \frac{M_{t}}{P_{t}} & =\frac{W_{t}}{P_{t}} .
\end{aligned}
$$

The Bellman equation can be written as

$$
V(P, A, \Omega)=\Pi(P, A, \Omega)+\mathbb{E}\left[\frac{1}{1+r_{t}}\{V\left(P, A^{\prime}, \Omega^{\prime}\right)+\underbrace{\lambda\left(L\left(P, A^{\prime}, \Omega^{\prime}\right)\right) L\left(P, A^{\prime}, \Omega^{\prime}\right) W\left(\Omega^{\prime}\right)}_{\text {adjustment gain }}\}\right],
$$

where $\Omega \equiv\left(z_{t}, r_{t-1}, \Psi_{t-1}\right)$ is the aggregate state, with $\Psi_{t-1}$ being the lagged distribution of firms over prices and productivity levels. Finally, the labor-market-clearing condition implies that $N_{t}=\Delta_{t}^{\mathrm{w}} C_{t}$, where

$$
\Delta_{t}^{\mathrm{w}}=\int_{0}^{1} A_{i, t}^{-1}\left(\frac{P_{i, t}}{P_{t}}\right)^{-\varepsilon} d i
$$

is the Dixit-Stiglitz, productivity-weighted measure of price dispersion.

\subsection{An Alternative Model with Sales}

The empirical analysis shows that sales have a strong effect on data properties. Models without sales considered in the previous section cannot match even the direction of the relationship between price dispersion and inflation for posted prices. To match the data with sales, one arguably needs a model with sales. As sales interact with regular prices, a model with sales has the potential to also improve the matching properties of regular prices, relative to a similar model without sales.

Based on the analysis in the previous section, the SSDP model would be a good candidate into which to introduce sales. However, as the model is relatively complex, adding sales would make it intractable. In light of this complexity, I consider a time-dependent model with sales. I do so for the following reasons: First, a calibrated version of the SSDP model suggests that pricing is time-dependent more than statedependent. Second, the Calvo model with sales moves the comovement in the simulated data closer to that in the actual data; the FMC model does the opposite. (As the previous section suggests, in order to match the data on price dispersion and inflation, the Calvo model needs more price flexibility, while 
the FMC model needs less. As sales add flexibility to pricing, I argue that they should be introduced into the Calvo model.) Finally, this guess is verified below by the finding that the Calvo model with sales can match the comovement in regular and posted prices reasonably well.

To model sales, I follow Guimaraes and Sheedy (2011). ${ }^{51}$ In this model, consumers have a preference for a variety of goods, and a variety of brands are nested within each product. There are two types of consumers: "loyals," who consume only one particular brand within each product, and "bargain hunters," who view brands within a product as close substitutes. This setup leads to an equilibrium in mixed strategies: firms alter the price between high—-to extract surplus from loyals—and low (sales) — to attract bargain hunters. This approach builds on the existing industrial organization literature, which has long emphasized that heterogeneity across consumers can be an important source of price dispersion. ${ }^{52}$

The key feature of this model is that sales are strategic substitutes. Firms have more incentive to hold sales when other firms charge a regular price. When a firm does not have a chance to change its regular price, it can still set a temporary, sale price. Essentially, sales relax the degree of price rigidity, which helps to match the data, since the Calvo model without sales produces too much volatility in price dispersion.

Specifically, let $\mathscr{G}$ be a set of goods of measure one, and $\mathscr{B}$ be a set of brands for each good. For a given household, there is a set of goods $\Lambda \subset \mathscr{G}$ for which the household is loyal to a particular brand within this good. Denote the brand to which the household is loyal to as $\mathscr{B}(i), i \in \Lambda$. For all other goods $(\mathscr{G} \backslash \Lambda)$, the household is a bargain hunter-that is, it obtains utility from consuming a variety of brands within each good. The Dixit-Stiglitz consumption aggregator can be written as

$$
C=\left(\int_{\Lambda} C_{i, \mathscr{B}(i)}^{\frac{\varepsilon-1}{\varepsilon}} d i+\int_{\mathscr{G} \backslash \Lambda}\left(\int_{\mathscr{B}} C_{i, b}^{\frac{\eta-1}{\eta}} d b\right)^{\frac{\eta}{\varepsilon}} d i\right)^{\frac{\varepsilon}{\varepsilon-1}}
$$

where $\varepsilon$ is the elasticity of substitution between goods, and $\eta$ is the elasticity of substitution between brands of the same good, with $\eta>\varepsilon$.

These preferences are further embedded into the Erceg, Henderson, and Levin (2000) environment with time-dependent nominal rigidities. The driving force of economic dynamics is a monetary shock, which is modeled as an innovation to the Friedman rule. In particular, the growth rate of money supply is given by

$$
\log \mu_{t}=\rho_{M} \log \mu_{t-1}+\varepsilon_{t}^{\mu}
$$

with $\varepsilon_{t}^{\mu} \stackrel{\text { iid }}{\sim} N\left(0,\left(1-\rho_{M}\right) \sigma_{M}\right)$, where $\mu_{t}$ is the growth rate of money supply, $\varepsilon_{t}^{\mu}$ is a monetary shock, $\rho_{M}$ is the persistence of money supply growth, and $\sigma_{M}$ is its volatility.

\footnotetext{
${ }^{51}$ Here, I describe only the main building blocks of the model. For full details, see the original paper.

${ }^{52}$ One could also consider alternative models of sales such as Kehoe and Midrigan (2014). In the Calvo version of their model, they introduce the probability of being able to reset the price temporarily, along with the standard Calvo probability to reset the price permanently. Hence, in this model, sales are introduced exogenously, while Guimaraes and Sheedy (2011) endogenize sales.
} 


\section{Price Dispersion and Inflation in the Models}

\subsection{Calibration and Simulation}

To calibrate the models, I closely follow the existing literature. Namely, for the SSDP model, I take the parameter values from Costain and Nakov (2011a,b), while for the GS model, from Guimaraes and Sheedy (2011). However, I deviate from the original papers on two occasions, due to discrepancies between calibration targets. First, supermarket prices exhibit high trend inflation. Therefore, I pick the value of trend inflation that matches the annual inflation rate for food items provided by the BLS-which is close to that in the IRI data. ${ }^{53}$ Second, the GS model calibrates the frequency of sales using the BLS data, while Coibion, Gorodnichenko, and Hong (2015) report that the frequency of sales in the IRI data is much higher. Following Guimaraes and Sheedy (2011), I recalibrate the elasticity of substitution across brands and across goods to match the target in my data. Table 4 summarizes the parameter values.

Panel A of Table 4 is dedicated to the SSDP model. Utility function parameters in Equation (8)$\beta, \gamma, \varepsilon, \chi, \nu$-are taken from Golosov and Lucas (2007). Parameters of the price-adjustment function- $\alpha$, $\bar{\lambda}$, and $\xi$ in Equation (7)—are chosen by Costain and Nakov (2011a,b) to minimize the distance between the model and the data for the frequency and distribution of price changes. The two limiting cases (Calvo and FMC) require specific values of the parameters $\bar{\lambda}$ and $\alpha$, respectively. The parameters that govern the monetary policy rule $-\varphi_{R}, \varphi_{\pi}, \varphi_{C}$ in Equation (12)—and shocks' persistence- $\varphi_{M}$ in Equation (14) and the autoregressive coefficient for $\varepsilon_{i, t}^{A}$ in Equation (11), $\varphi_{A}$-are taken from Costain and Nakov (2011a). Finally, I set trend inflation ( $\bar{\pi}$ ) to match the annualized inflation rate in the BLS data.

Panel B of Table 4 summarizes the GS model calibration. To avoid confusion and for ease of reference, I stick with the original notation, at the cost of using different notation for the same parameters in the two models. As mentioned above, I set the elasticity of substitution between brands to a lower value than in GS (16.45 vs. 19.8), while the elasticity of substitution across goods is increased (3.15 vs. 3.01). Note that the former parameter has no counterpart in the data and is not directly observable. Both this paper and GS calibrate these parameters to match the frequency of sales. However, the target frequency in their paper (7.4 percent) based on Nakamura and Steinsson (2008) is much smaller than the frequency of sales observed in the data used in this paper (depending on the measure, from 19.5 percent to 23.7 percent-see Coibion, Gorodnichenko, and Hong 2015 for details). The baseline parameters chosen here allow the model to match the comovement of price dispersion in regular and posted prices, only negligibly overstating the frequency of sales (24.8 percent). I then compare the results for my baseline calibration with the case of the GS parameterization.

I generate a history of shocks for 2,200 periods, burning the first 200 observations, and compute price dispersion and inflation in the model. I consider three cases for different sources of variation: monetary shocks only, TFP shocks only, and both types of shocks together.

I compare the Calvo, FMC, SSDP, and GS models by estimating the comovement of price dispersion and inflation for the simulated data based on the reduced-form relationship. As discussed earlier, the reduced-form specification is suggested by the data and is less fragile since it does not include higherorder terms. In addition, the structural relationship is valid only for the Calvo model; the analog is not

\footnotetext{
${ }^{53}$ Taking the trend inflation rate from the IRI data does not alter the qualitative conclusions. I use the BLS data estimates for more consistency with the original papers.
} 
Table 4. SSDP Model Calibration

\begin{tabular}{|c|c|c|c|c|c|}
\hline \multicolumn{3}{|c|}{ Panel A: Generic SSDP without sales } & \multicolumn{3}{|c|}{ Panel B: Calvo with sales } \\
\hline & $\begin{array}{l}\text { Notation } \\
\text { (1) }\end{array}$ & $\begin{array}{c}\text { Value } \\
(2)\end{array}$ & & $\begin{array}{l}\text { Notation } \\
\text { (3) }\end{array}$ & $\begin{array}{c}\text { Value } \\
\text { (4) }\end{array}$ \\
\hline \multicolumn{6}{|c|}{ Preferences \& Technology } \\
\hline Discount factor & $\beta$ & $1.04^{-\frac{1}{12}}$ & Discount factor & $\beta$ & $1.03^{-\frac{1}{12}} \mathrm{rel}$ \\
\hline Intertemporal ES & $\gamma$ & 2 & Intertemporal ES & $\theta_{c}$ & 0.333 \\
\hline ES across goods & $\varepsilon$ & 7 & ES across goods & $\varepsilon$ & 3.15 \\
\hline Disutility of labor & $\chi$ & 6 & ES across brands & $\eta$ & 16.45 \\
\hline \multirow[t]{3}{*}{ Money demand } & $v$ & 1 & Frisch LS elasticity & $\theta_{h}$ & 0.7 \\
\hline & & & $L$ Elasticity of $Y$ & $\alpha$ & 0.667 \\
\hline & & & ES across labor & 5 & 20 \\
\hline \multicolumn{6}{|c|}{ Pricing } \\
\hline Smoothness & $\xi$ & 0.23 & Price stickiness & $\phi_{p}$ & 0.889 \\
\hline Menu cost & $\alpha$ & 0.037 & Wage stickiness & $\phi_{W}$ & 0.889 \\
\hline Calvo & $\bar{\lambda}$ & 0.110 & & & \\
\hline Menu cost in the limit & $\alpha$ & 0.065 & Fraction of loyals & $\lambda$ & 0.735 \\
\hline Calvo in the limit & $\bar{\lambda}$ & 0.1 & Size of sales sector & $\sigma$ & 0.255 \\
\hline \multicolumn{6}{|c|}{ Shocks } \\
\hline Monetary persistence & $\varphi_{M}$ & 0 & Monetary persistence & $\rho_{M}$ & 0.536 \\
\hline TFP Persistence & $\varphi_{A}$ & 0.95 & Monetary volatility & $\sigma_{M}$ & 0.02 \\
\hline \multicolumn{6}{|c|}{ Policy } \\
\hline Annualized trend inflation & $\bar{\pi}$ & $4.4 \%$ & & & \\
\hline Interest rate smoothing & $\varphi_{R}$ & 0.9 & & & \\
\hline Response to inflation & $\varphi_{\pi}$ & 4 & & & \\
\hline Response to output gap & $\varphi_{C}$ & 0.5 & & & \\
\hline
\end{tabular}

known for the FMC or SSDP model. As a counterpart of Equation (6), I estimate the following regression:

$$
\sigma_{t}=\beta \pi_{t}+\gamma+\varepsilon_{t}
$$

where $\sigma_{t}$ is the standard deviation of $\log$ prices simulated in the model and $\pi_{t}$ is the simulated inflation. I run the MA(12) filter on both series to make sure that my results are not driven by the effect of filtering on the persistence of these series or their comovement. I perform robustness checks by considering the same regressions without the filter, and obtain similar results.

\subsection{Matching the Comovement}

Table 5 compares the comovement of price dispersion and inflation in the data and in the models, for regular and posted prices. The Calvo model with sales outperforms any other model for both regular and posted prices. The degree of the comovement, $\beta$, is $-0.033(-0.022$ in the data) for posted prices and 0.033 (0.026 in the data) for regular prices. Without sales, the Calvo model's $\beta$ is more than 15 times greater (for the baseline calibration) than in the data for regular prices, and the negative comovement for posted prices cannot be achieved at all (alternative calibrations are discussed later in this section). ${ }^{54}$ In the baseline FMC specification (no sales), $\beta$ is very small: 5 times smaller than in the data. Sales give firms an opportunity to change their posted prices when their regular prices are rigid, thereby reducing price rigidity in the otherwise Calvo setup. However, unlike increasing the price flexibility parameter in the Calvo model, introducing sales does not lead to a counterfactual frequency of regular price changes. Sales also help to differentiate between the comovement in regular and posted prices, which are different

\footnotetext{
${ }^{54}$ Appendix H confirms the Calvo model's inability to match the data using the structural specification discussed in Section 3.2.
} 


\begin{tabular}{lcc}
\hline \hline & $\begin{array}{c}\text { Regular } \\
\text { Prices } \\
(1)\end{array}$ & $\begin{array}{c}\text { Posted } \\
\text { Prices } \\
(2)\end{array}$ \\
\hline & 0.026 & -0.022 \\
Data & 0.033 & -0.033 \\
Models & 0.157 & \\
$\quad$ Calvo with Sales & 0.005 & \\
$\quad$ Smoothly State-Dependent Pricing & 0.505 & \\
$\quad$ Fixed Menu Costs & \\
$\quad$ Standard Calvo (no sales) & & \\
\hline Source: Author's calculations based on the IRI and model-simulated data. \\
$\begin{array}{l}\text { Notes: The table reports slope coefficients of the regression of price dispersion on infla- } \\
\text { tion in the actual data (see Table 2) and those simulated by four models. The columns } \\
\text { distinguish between posted and regular prices. }\end{array}$
\end{tabular}

in the data.

The fact that without sales these basic models cannot match the data is quite intuitive. In the Calvo model, a large nominal shock does not affect the number of firms that adjust their prices. If the frequency of price adjustment is small, very few firms change their prices, thereby having only a small effect on the aggregate price level. At the same time, firms that are able to reset their prices adjust them significantly, thereby increasing price dispersion. Hence, nominal shocks have a small effect on inflation and a quantitatively large effect on price dispersion. In terms of the estimated comovement, small changes in inflation are associated with large changes in price dispersion, implying a relatively large coefficient. To match the data, more firms have to adjust their prices, amplifying the response of inflation and damping the response of price dispersion. Instead, in the FMC model the comovement is low: Firms set their prices by the $(S, s)$ rule. A nominal shock forces "marginal" firms to adjust, thereby having a strong effect on inflation but only a limited effect on the dispersion of relative prices. Consequently, the change in price dispersion is small relative to the change in inflation. If the menu cost is very small, most firms will adjust their prices to the same value, which may even lower price dispersion.

The SSDP model produces the comovement that lies between those in the Calvo and FMC models, and is about six times greater than in the data. Note that, as will be shown later, both versions of the model (the money growth and Taylor rule) produce similar estimates. The fact that the estimates lie between the Calvo model and the FMC model is quite intuitive: In the Calvo model, in the wake of an inflationary shock, every firm has an equal chance to reset the price. Hence, it is equally likely that a firm that lags behind the price level is able to adjust as that a firm with the highest price makes its good even dearer. In the FMC model, however, there is a strong selection effect: only firms that are far from the optimal price will adjust, partly offsetting the effect of inflation on price dispersion. As the SSDP model nests the Calvo and FMC models as special cases, its behavior depends strongly on the estimated parameters. Since Costain and Nakov's (2011a) estimates imply that the price-setting is closer to Calvo, it is no surprise that the relationship between inflation and price dispersion is also so. However, the data suggest that the estimated SSDP model is too close to Calvo, and that it overestimates the role of time-dependent frictions. Although in the data, price dispersion responds much more strongly to inflation than in the Golosov and Lucas (2007) model—clearly implying monetary non-neutrality—the degree of non-neutrality produced by the SSDP model may be overstated.

A strong aspect of the SSDP model is that by varying the smoothness parameter, $\xi$, one can achieve 
Figure 1. Smoothness Parameter in the SSDP Model

\section{A. Comovement of Price Dispersion and Inflation}

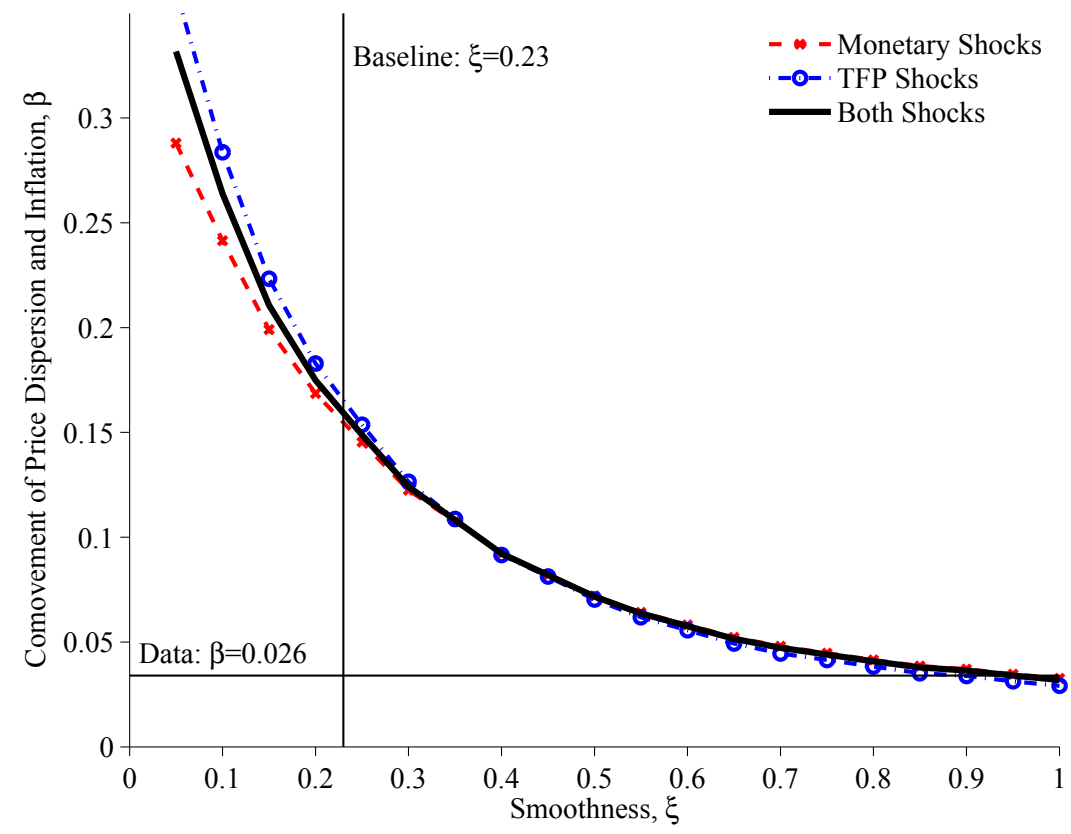

\section{B. Distribution of Price Changes}

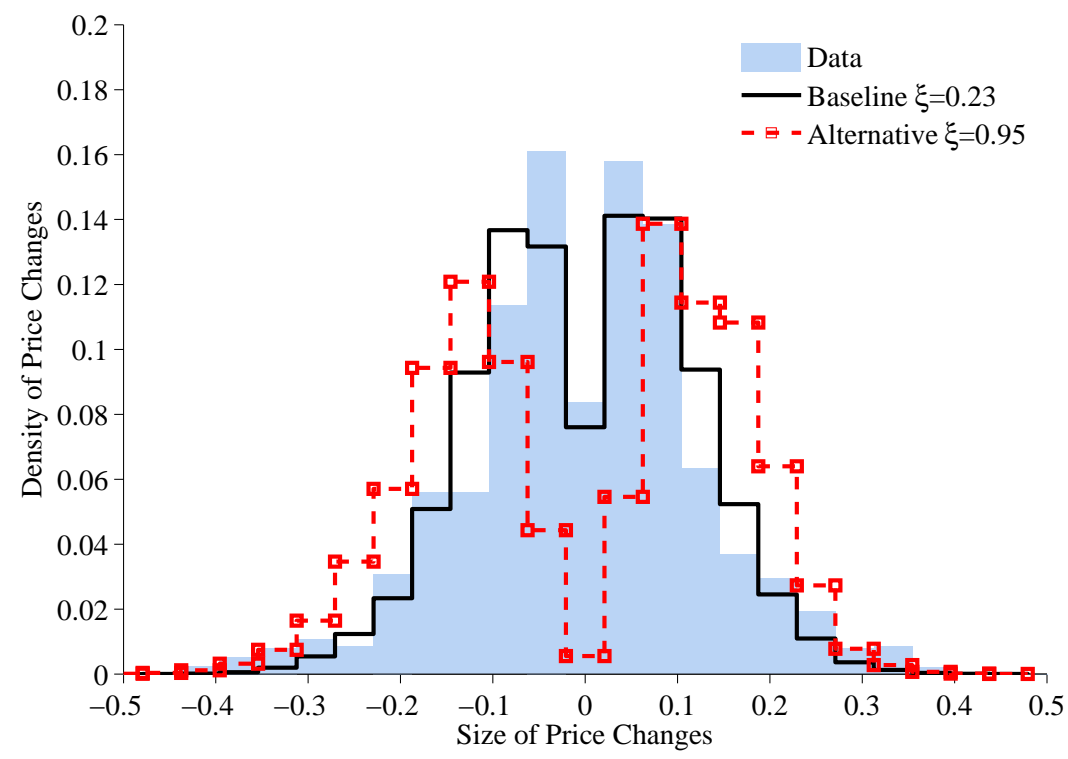

Source: Author's calculations based on simulated data. Blue filled histogram from Costain and Nakov (2011a, p. 647, fig. 1). Notes: Panel A depicts the estimated slope coefficients for the regression of price dispersion on inflation for the data simulated in the Smoothly State-Dependent Pricing (SSDP) model for monetary, TFP, and both shocks. Panel B demonstrates the distribution of the sizes of price changes (1) in the data, (2) in the model with the baseline value of the smoothness parameter $\xi=0.23$, and (3) in the model with the value of $\xi$ that matches the comovement of price dispersion and inflation in Panel $\mathrm{A}$, $\xi=0.95$. 
any intermediate case between strictly Calvo pricing and FMC pricing. As the former overestimates the degree of the comovement and the latter underestimates it, there exists a value of $\xi$ that allows matching it. Since the smoothness parameter is calibrated to match the distribution of the sizes of price changes in the data, matching price dispersion leads to mismatch in the distribution. This result is shown in Figure 1. Panel A shows the comovement of price dispersion and inflation for the three data-generating processes and different values of $\xi$. To match the comovement, $\xi$ should be set to approximately 0.95 , far above its baseline value of 0.23 . Hence, this implies that price-setting should be more state-dependent than suggested by the distribution of the sizes of price changes. Panel B confirms this intuition: for the new value of $\xi$, the histogram of price changes looks close to a bimodal distribution-with almost no price changes around zero, in contrast to the data (Midrigan 2011).

Sensitivity to Choice of Parameters Table 6 examines the results' sensitivity to alternative calibrations of key parameters. Panel A presents the results for the Calvo model without sales. First, it shows that $\beta$ is not affected much by the shocks that generate the comovement. For example, $\beta$ obtained from both monetary and TFP shock is 0.505 , close to that obtained from TFP shocks only (0.547) or monetary shocks only (0.388) - and both are far from the data (0.026). This is not surprising because in the Calvo model, the effect of shocks on the comovement appears only in the higher-order terms of quadratic approximation. Second, changing the persistence of shocks or the central bank's response to inflation does not make a qualitative difference, although a lower persistence of TFP shocks, $\varphi_{A}$, somewhat changes the comovement quantitatively; lowering $\varphi_{A}$ from 0.95 in the baseline to 0.4 reduces $\beta$ to 0.292 . Third, even without trend inflation, the Calvo model overestimates the comovement by a factor of eight. To match the data, prices should be extremely flexible: the monthly frequency of price adjustment should be 0.5 (compare to 0.1 in the data). However, such a frequency is at odds with the observed duration of price spells. The result for the higher $\bar{\lambda}$ is similar to the one for the higher $\xi$.

Panels B and C of Table 6 do a similar exercise for the FMC and SSDP models, respectively. Those two models show even more robustness to the choice of calibration targets than the Calvo model does. Changing the persistence of shocks, the size of menu costs, or removing trend inflation does not make the estimates close to the data. Unlike in the Calvo model, varying the size of menu costs in the FMC model does not allow matching the data. Consistent with the theoretical reasoning discussed earlier, when the menu cost is very small, the FMC model's $\beta$ may even become negative. Interestingly, in the SSDP model, when monetary policy adheres to constant money growth, the comovement is virtually the same as in the Taylor rule case.

Finally, Panel D of Table 6 considers alternative parameterizations of the GS model (Calvo with sales). The volatility of shocks, degree of price stickiness, fraction of loyal customers, and elasticity of substitution across goods or across brands each has a strong effect on the comovement, while wage stickiness, the persistence of shocks, and the sales sector's share does not. The share of the sales sector, instead, has a much stronger effect on the frequency of sales. Note that under the GS original calibration, the comovement moves further away from the data, due to the mismatch of the frequency of sales. However, the GS calibration with highly volatile monetary shocks gets reasonably close to the data.

To summarize, although the comovement of price dispersion and inflation clearly depends on the choice of parameter values, models without sales are unable to match the comovement observed in the 
Table 6. Sensitivity to Parameters Choice

\begin{tabular}{|c|c|c|c|c|}
\hline & \multicolumn{3}{|c|}{ Regular Prices } & \multirow{2}{*}{$\begin{array}{c}\text { Posted Prices } \\
\text { Monetary } \\
\text { (4) }\end{array}$} \\
\hline & $\begin{array}{l}\text { Monetary } \\
\text { (1) }\end{array}$ & $\begin{array}{l}\text { TFP } \\
(2)\end{array}$ & $\begin{array}{c}\text { Both Shocks } \\
\text { (3) }\end{array}$ & \\
\hline \multicolumn{5}{|c|}{ Panel A: Standard Calvo (no sales) } \\
\hline Baseline & 0.388 & 0.547 & 0.505 & \\
\hline Response to Inflation $\varphi_{\pi}=10$ (4) & 0.380 & 0.545 & 0.462 & \\
\hline Persistence of TFP Shock $\varphi_{A}=0.4(0.95)$ & 0.388 & 0.292 & 0.388 & \\
\hline Persistence of M Shock $\varphi_{M}=0.8(0)$ & 0.420 & 0.547 & 0.427 & \\
\hline Trend Inflation $\bar{\pi}=0(4.4 \%)$ & 0.181 & 0.229 & 0.209 & \\
\hline Probability of Price Change $\bar{\lambda}=0.5(0.1)$ & 0.041 & 0.038 & 0.041 & \\
\hline \multicolumn{5}{|c|}{ Panel B: Fixed Menu Costs } \\
\hline Baseline & 0.007 & 0.004 & 0.005 & \\
\hline Persistence of TFP Shock $\varphi_{A}=0.4(0.95)$ & 0.007 & 0.001 & 0.007 & \\
\hline Persistence of M Shock $\varphi_{M}=0.8(0)$ & 0.007 & 0.004 & 0.007 & \\
\hline Trend Inflation $\bar{\pi}=0(4.4 \%)$ & 0.011 & 0.009 & 0.010 & \\
\hline Menu Cost $\alpha=0.005(0.065)$ & -0.000 & -0.001 & -0.002 & \\
\hline Menu Cost $\alpha=0.15(0.065)$ & 0.007 & 0.004 & 0.006 & \\
\hline \multicolumn{5}{|c|}{ Panel C: Smoothly State-Dependent Pricing } \\
\hline Baseline (Taylor Rule Setup) & 0.153 & 0.162 & 0.157 & \\
\hline Money Growth Setup & 0.157 & 0.150 & 0.154 & \\
\hline Response to Inflation $\varphi_{\pi}=10$ (4) & 0.151 & 0.156 & 0.153 & \\
\hline Persistence of TFP Shock $\varphi_{A}=0.4$ (0.95) & 0.153 & 0.135 & 0.152 & \\
\hline Persistence of M Shock $\varphi_{M}=0.8(0)$ & 0.156 & 0.162 & 0.156 & \\
\hline Trend Inflation $\bar{\pi}=0(4.4 \%)$ & 0.112 & 0.116 & 0.114 & \\
\hline \multicolumn{5}{|c|}{ Panel D: Calvo with Sales } \\
\hline Baseline & -0.033 & & & 0.033 \\
\hline GS, 2 sectors & -0.135 & & & -0.000 \\
\hline GS, 1 sector & -0.095 & & & -0.003 \\
\hline GS, Volatility of M Shock $\sigma_{M}=0.2(0.02)$ & 0.047 & & & -0.022 \\
\hline Volatility of M Shock $\sigma_{M}=0.2(0.02)$ & 0.182 & & & 0.056 \\
\hline Persistence of M Shock $\rho_{M}=0(0.536)$ & 0.033 & & & -0.035 \\
\hline Price Stickiness $\phi_{p}=0.65(0.889)$ & 0.001 & & & -0.008 \\
\hline Wage Stickiness $\phi_{W}=0.65(0.889)$ & 0.029 & & & -0.037 \\
\hline ES across Brands $\eta=19.8(16.45)$ & 0.002 & & & -0.138 \\
\hline ES across Goods $\epsilon=3.01(3.15)$ & 0.012 & & & -0.127 \\
\hline Fraction of Loyal Customers $\lambda=0.95(0.735)$ & 0.014 & & & -0.110 \\
\hline Share of Sales Sector $\sigma=1(0.255)$ & 0.027 & & & -0.019 \\
\hline
\end{tabular}

Source: Author's calculations based on simulated data.

Notes: The table reports estimates presented in Table 5 for alternative parameter values. Panel A focuses on the Calvo model without sales, Panel B on the FMC model, Panel C on the SSDP model, and Panel D on the GS model. The variation in Columns (1)-(3) comes from monetary, TFP, and both shocks, respectively. Column (4) presents the results for posted prices.

data without making counterfactual assumptions about the frequency or size of price changes. Introducing sales makes the comovement very close to the one in the data. Qualitatively, the result is not sensitive to a particular calibration approach, and the baseline calibration using the parameters that are widely accepted in the literature and that match basic pricing moments can match the comovement in the data quantitatively. 


\section{Concluding Remarks}

This paper measures price dispersion in scanner data from grocery and drug stores, and then studies whether workhorse macro models can match its key properties such as the comovement with inflation. It finds a nontrivial degree of price dispersion, which cannot be fully explained by heterogeneity in the terms of sale or shopping experience, hinting that other factors, such as price stickiness, play a role. It then focuses on workhorse models, which include various frictions in price adjustment but do not include sales, and shows that although qualitatively they support regular-price data, they are still quite far quantitatively. I show that extending a workhorse model to include sales brings it quantitatively close to the data, due to the interaction between sale and regular prices-a novel result by itself. I conclude that models with sales have much greater potential to explain aggregate data patterns than previously thought.

This paper's results have a number of implications. First, welfare measurement should be anchored to the price dispersion observed in the data. As the datasets on disaggregated prices become widely available-and computational costs of processing those data fall-there is no reason why researchers could not or should not use price dispersion measured directly from the data. Second, models that intend to match micro pricing data should not treat sales purely as noise, since not only do the properties of sale prices differ from those of regular prices but also sales can interact with regular prices. A model with sales is more successful in matching the properties of regular prices than a similar model without sales. Moreover, the frequency of sales in the data is a key calibration target that allows matching the properties of regular prices. Finally, macroeconomic models of price stickiness should aim at matching price dispersion in the data, in addition to the usually targeted frequency, size, and distribution of price changes, since these measures are interrelated and all of them have implications for the overall degree of stickiness and non-neutrality of monetary shocks.

As this paper presents one of the first attempts to study price dispersion in the context of price rigidity and sales, I hope that future research will address some of its limitations. Theoretical models analyzed here generate the comovement of price dispersion and inflation due to monetary and productivity shocks, both aggregate and idiosyncratic. As other types of shocks have proved dominant in the data, extending the models to allow for them could bring theory and data closer together. This is especially true for financial shocks, which were at play during the onset of the Great Recession (Chodorow-Reich 2014), or for energy-price shocks, given their historic effect on inflation. We also need more data on price dispersion from sectors other than fast-moving consumer goods (FMCG), for which scanner data are widely available and used. Although FMCG, no doubt, is a large sector that covers 10-15 percent of output, it has special properties that may differ from the properties of other sectors (for example, in the prevalence of sales). Specifically, we know much less about the dispersion of durables, wholesale, or intermediate-good prices. Finally, I hope that macro theorists will spend more time linking price dispersion to welfare. Currently, in many workhorse models, price dispersion has a negative effect on welfare due to the misallocation effect, as sticky prices interfere with consumption smoothing across varieties. However, price dispersion may also have a positive effect on welfare, as it provides an opportunity for consumers with low search costsand typically low consumption and high marginal utility—to reallocate their consumption toward cheaper goods, which should raise aggregate welfare. ${ }^{55}$ For example, it allows the unemployed to use their time

\footnotetext{
${ }^{55}$ For example, Head and Kumar (2005) study inflation, price dispersion, and welfare in a search model.
} 
more productively by searching for best deals. It would also be interesting to see how sales can interact with search frictions. Sales are likely to be more prevalent when search costs are low. Although the effect of this interaction is an interesting exercise, the key inconsistency that search models should overcome is their inability to generate dynamic responses, an inconsistency that cannot be remedied mechanically by the introduction of sales.

\section{References}

Akerlof, George A., and Janet L. Yellen. 1985. "A Near-Rational Model of the Business Cycle, with Wage and Price Intertia." Quarterly Journal of Economics 100(5): 823-838.

Alvarez, Fernando, and Francesco Lippi. 2014. "Price Setting with Menu Cost for Multiproduct Firms." Econometrica 82(1): 89-135.

Anderson, Eric, Emi Nakamura, Duncan Simester, and Jón Steinsson. 2013. "Informational Rigidities and the Stickiness of Temporary Sales." NBER Working Paper 19350.

Baharad, Eyal, and Benjamin Eden. 2004. "Price Rigidity and Price Dispersion: Evidence from Micro Data." Review of Economic Dynamics 7(3): 613-641.

Ball, Laurence, and David Romer. 1990. "Real Rigidities and the Non-Neutrality of Money." Review of Economic Studies 57(2): 183-203.

Baye, Michael R., J. Rupert J. Gatti, Paul Kattuman, and John Morgan. 2009. "Clicks, Discontinuities, and Firm Demand Online." Journal of Economics \& Management Strategy 18(4): 935-975.

Baye, Michael R., John Morgan, and Patrick Scholten. 2004. "Price Dispersion in the Small and in the Large: Evidence from an Internet Price Comparison Site." Journal of Industrial Economics 52(4): 463-496.

. 2010. "Information, Search, and Price Dispersion." In Economics and Information Systems, Handbooks in Information Systems, vol. 1, edited by Terrence Hendershott, chap. 6. Emerald, 323-376.

Benabou, Roland. 1988. "Search, Price Setting and Inflation." Review of Economic Studies 55(3): 353-376.

—. 1992. "Inflation and Efficiency in Search Markets." Review of Economic Studies 59(2): 299-329.

1993. "Search Market Equilibrium, Bilateral Heterogeneity, and Repeat Purchases." Journal of Economic Theory 60(1): 140-158.

Boivin, Jean, Robert Clark, and Nicolas Vincent. 2012. "Virtual Borders." Journal of International Economics 86(2): 327-335.

Bronnenberg, Bart J., Michael W. Kruger, and Carl F. Mela. 2008. "Database Paper-The IRI Marketing Data Set." Marketing Science 27(4): 745-748.

Brynjolfsson, Erik, and Michael D. Smith. 2000. "Frictionless Commerce? A Comparison of Internet and Conventional Retailers." Management Science 46(4): 563-585.

Burdett, Kenneth, and Kenneth L. Judd. 1983. "Equilibrium Price Dispersion.” Econometrica 51(4): 955-969.

Calvo, Guillermo A. 1983. "Staggered Prices in a Utility-Maximizing Framework." Journal of Monetary Economics 12(3): 383-398.

Carvalho, Carlos. 2006. "Heterogeneity in Price Stickiness and the Real Effects of Monetary Shocks." B.E. Journal of Macroeconomics 6(3): 1-58.

Chevalier, Judith, and Austan Goolsbee. 2003. "Measuring Prices and Price Competition Online: Amazon.com and BarnesandNoble.com." Quantitative Marketing and Economics 1(2): 203-222. 
Chevalier, Judith A., and Anil K. Kashyap. 2011. "Best Prices.” NBER Working Paper 16680.

Chodorow-Reich, Gabriel. 2014. "The Employment Effects of Credit Market Disruptions: Firm-Level Evidence from the 2008-9 Financial Crisis." Quarterly Journal of Economics 129(1): 1-59.

Choi, Chi-Young. 2010. "Reconsidering the Relationship between Inflation and Relative Price Variability." Journal of Money, Credit and Banking 42(5): 769-798.

Clark, Robert, and Nicolas Vincent. 2014. "Booms, Busts, and Price Dispersion.” Economics Letters 124(3): 399-401.

Coibion, Olivier, Yuriy Gorodnichenko, and Gee Hee Hong. 2015. "The Cyclicality of Sales, Regular and Effective Prices: Business Cycle and Policy Implications.” American Economic Review 105(3): 993-1029.

Coibion, Olivier, Yuriy Gorodnichenko, and Johannes Wieland. 2012. "The Optimal Inflation Rate in New Keynesian Models: Should Central Banks Raise Their Inflation Targets in Light of the Zero Lower Bound?" Review of Economic Studies 79(4): 1371-1406.

Costain, James, and Anton Nakov. 2011a. "Distributional Dynamics under Smoothly State-Dependent Pricing." Journal of Monetary Economics 58(6): 646-665.

. 2011b. "Price Adjustments in a General Model of State-Dependent Pricing." Journal of Money, Credit and Banking 43(2-3): 385-406.

Debelle, Guy, and Owen Lamont. 1997. "Relative Price Variability and Inflation: Evidence from U.S. Cities." Journal of Political Economy 105(1): 132-152.

Diamond, Peter A. 1971. "A Model of Price Adjustment." Journal of Economic Theory 3(2): 156-168. 1993. "Search, Sticky Prices, and Inflation." Review of Economic Studies 60(1): 53-68.

Dotsey, Michael, Robert G. King, and Alexander L. Wolman. 1999. "State-Dependent Pricing and the General Equilibrium Dynamics of Money and Output." Quarterly Journal of Economics 114(2): 655-690.

Driscoll, John C., and Aart C. Kraay. 1998. "Consistent Covariance Matrix Estimation with Spatially Dependent Panel Data." Review of Economics and Statistics 80(4): 549-560.

Eden, Benjamin. 1994. "The Adjustment of Prices to Monetary Shocks When Trade Is Uncertain and Sequential." Journal of Political Economy 102(3): 493-509.

. 2001. "Inflation and Price Adjustment: An Analysis of Microdata." Review of Economic Dynamics 4(3): 607-636.

Eichenbaum, Martin, Nir Jaimovich, Sergio Rebelo, and Josephine Smith. 2014. "How Frequent Are Small Price Changes?" American Economic Journal: Macroeconomics 6(2): 137-155.

Erceg, Christopher J., Dale W. Henderson, and Andrew T. Levin. 2000. "Optimal Monetary Policy with Staggered Wage and Price Contracts." Journal of Monetary Economics 46(2): 281-313.

Gagnon, Étienne. 2009. "Price Setting during Low and High Inflation: Evidence from Mexico." Quarterly Journal of Economics 124(3): 1221-1263.

Gagnon, Étienne, David López-Salido, and Nicolas Vincent. 2013. "Individual Price Adjustment along the Extensive Margin." In NBER Macroeconomics Annual 2012, vol. 27, edited by Daron Acemoglu, Jonathan A. Parker, and Michael Woodford, chap. 4. University of Chicago Press, 235-281.

Glandon, Jr., Philip J. 2011. "Sales and the (Mis)Measurement of Price Level Fluctuations." Unpublished Manuscript. Available at https://my.vanderbilt.edu/pglandon/files/2011/10/Glandon_Sales_Oct_231.pdf .

Golosov, Mikhail, and Robert E. Lucas, Jr. 2007. "Menu Costs and Phillips Curves." Journal of Political Economy 115(2): 171-199. 
Gorodnichenko, Yuriy, Viacheslav Sheremirov, and Oleksandr Talavera. 2014. "Price Setting in Online Markets: Does IT Click?” NBER Working Paper 20819.

Gorodnichenko, Yuriy, and Oleksandr Talavera. 2014. "Price Setting in Online Markets: Basic Facts, International Comparisons, and Cross-Border Integration." NBER Working Paper 20406.

Grier, Kevin B., and Mark J. Perry. 1996. "Inflation, Inflation Uncertainty, and Relative Price Dispersion: Evidence from Bivariate GARCH-M Models." Journal of Monetary Economics 38(2): 391-405.

Guimaraes, Bernardo, and Kevin D. Sheedy. 2011. "Sales and Monetary Policy." American Economic Review 101(2): 844-876.

Head, Allen, and Alok Kumar. 2005. "Price Dispersion, Inflation, and Welfare." International Economic Review 46(2): 533-572.

Head, Allen, Lucy Qian Liu, Guido Menzio, and Randall Wright. 2012. "Sticky Prices: A New Monetarist Approach." Journal of the European Economic Association 10(5): 939-973.

Jordà, Òscar. 2005. "Estimation and Inference of Impulse Responses by Local Projections." American Economic Review 95(1): 161-182.

Kaplan, Greg, and Guido Menzio. 2014. “The Morphology of Price Dispersion.” International Economic Review, forthcoming.

Kehoe, Patrick J., and Virgiliu Midrigan. 2014. "Prices Are Sticky After All.” Journal of Monetary Economics, forthcoming.

Konieczny, Jerzy D., and Andrzej Skrzypacz. 2005. "Inflation and Price Setting in a Natural Experiment." Journal of Monetary Economics 52(3): 621-632.

Kruger, Michael W., and Daniel Pagni. 2008. "IRI Academic Data Set Description." Version 2.1, Information Resources Incorporated.

Lach, Saul. 2002. "Existence and Persistence of Price Dispersion: An Empirical Analysis." Review of Economics and Statistics 84(3): 433-444.

Lach, Saul, and Daniel Tsiddon. 1992. "The Behavior of Prices and Inflation: An Empirical Analysis of Disaggregated Price Data.” Journal of Political Economy 100(2): 349-389.

Love, Inessa, and Lea Zicchino. 2006. "Financial Development and Dynamic Investment Behavior: Evidence From Panel VAR." Quarterly Review of Economics and Finance 46(2): 190-210.

MacMinn, Richard D. 1980. "Search and Market Equilibrium." Journal of Political Economy 88(2): 308-327.

Mankiw, N. Gregory. 1985. "Small Menu Costs and Large Business Cycles: A Macroeconomic Model." Quarterly Journal of Economics 100(2): 529-538.

Midrigan, Virgiliu. 2011. "Menu Costs, Multiproduct Firms, and Aggregate Fluctuations." Econometrica 79(4): 1139-1180.

Nakamura, Alice O., Emi Nakamura, and Leonard I. Nakamura. 2011. "Price Dynamics, Retail Chains and Inflation Measurement." Journal of Econometrics 161(1): 47-55.

Nakamura, Emi, and Jón Steinsson. 2008. "Five Facts about Prices: A Reevaluation of Menu Cost Models." Quarterly Journal of Economics 123(4): 1415-1464.

— 2013. "Price Rigidity: Microeconomic Evidence and Macroeconomic Implications." Annual Review of Economics 5(1): 133-163.

Phillips, Peter C. B. 1988. "Regression Theory for Near-Integrated Time Series." Econometrica 56(5): 1021-1043. 
Pratt, John W., David A. Wise, and Richard Zeckhauser. 1979. "Price Differences in Almost Competitive Markets." Quarterly Journal of Economics 93(2): 189-211.

Reinganum, Jennifer F. 1979. “A Simple Model of Equilibrium Price Dispersion.” Journal of Political Economy 87(4): 851-858.

Reinsdorf, Marshall. 1994. "New Evidence on the Relation between Inflation and Price Dispersion." American Economic Review 84(3): 720-731.

Sheshinski, Eytan, and Yoram Weiss. 1977. "Inflation and Costs of Price Adjustment." Review of Economic Studies 44(2): 287-303.

—. 1983. "Optimum Pricing Policy under Stochastic Inflation." Review of Economic Studies 50(3): 513-529.

Silver, Mick, and Christos Ioannidis. 2001. "Intercountry Differences in the Relationship between Relative Price Variability and Average Prices." Journal of Political Economy 109(2): 355-374.

Sorensen, Alan T. 2000. "Equilibrium Price Dispersion in Retail Markets for Prescription Drugs." Journal of Political Economy 108(4): 833-862.

Stigler, George J. 1961. “The Economics of Information.” Journal of Political Economy 69(3): 213-225.

Stock, James H., and Mark W. Watson. 2007. "Why Has U.S. Inflation Become Harder to Forecast?" Journal of Money, Credit and Banking 39(s1): 3-33.

Taylor, John B. 1980. "Aggregate Dynamics and Staggered Contracts." Journal of Political Economy 88(1): 1-23.

Tommasi, Mariano. 1994. "The Consequences of Price Instability on Search Markets: Toward Understanding the Effects of Inflation." American Economic Review 84(5): 1385-1396.

Van Hoomissen, Theresa. 1988. "Price Dispersion and Inflation: Evidence from Israel." Journal of Political Economy 96(6): 1303-1314.

Varian, Hal R. 1980. "A Model of Sales." American Economic Review 70(4): 651-659.

Williamson, Stephen D. 1996. "Sequential Markets and the Suboptimality of the Friedman Rule." Journal of Monetary Economics 37(3): 549-572.

Woodford, Michael. 2003. Interest and Prices: Foundations of a Theory of Monetary Policy. Princeton University Press.

2009. "Information-Constrained State-Dependent Pricing." Journal of Monetary Economics 56(Suppl.): S100-S124. 


\section{Appendix}

\section{A Price Dispersion by Markets and Product Categories}

Table A1. Price Dispersion by Market and Product Category, log points

\begin{tabular}{|c|c|c|c|c|c|}
\hline \multicolumn{3}{|c|}{ Panel A: Markets } & \multicolumn{3}{|c|}{ Panel B: Product Categories } \\
\hline & $\begin{array}{l}\text { Posted } \\
\text { Price } \\
(1)\end{array}$ & $\begin{array}{l}\text { Regular } \\
\text { Price } \\
\text { (2) }\end{array}$ & & $\begin{array}{c}\text { Posted } \\
\text { Price } \\
(1)\end{array}$ & $\begin{array}{c}\text { Regular } \\
\text { Price } \\
(2)\end{array}$ \\
\hline Atlanta, GA & 7.3 & 4.6 & Beer & 5.6 & 4.8 \\
\hline Birmingham/Montgomery, AL & 9.2 & 6.2 & Blades & 8.1 & 6.4 \\
\hline Boston, MA & 10.5 & 8.4 & Carbonated Beverages & 13.6 & 8.2 \\
\hline Buffalo/Rochester, NY & 7.6 & 5.5 & Cigarettes & 7.8 & 7.5 \\
\hline Charlotte, NC & 8.4 & 5.4 & Coffee & 9.9 & 6.8 \\
\hline Chicago, IL & 11.3 & 8.3 & Cold Cereal & 13.2 & 7.5 \\
\hline Cleveland, $\mathrm{OH}$ & 5.6 & 3.0 & Deodorants & 12.1 & 9.1 \\
\hline Dallas, TX & 10.5 & 7.8 & Diapers & 6.4 & 4.6 \\
\hline Des Moines, IA & 7.8 & 6.2 & Facial Tissues & 11.8 & 8.0 \\
\hline Detroit, MI & 10.1 & 6.6 & Frozen Dinner & 11.6 & 7.4 \\
\hline Eau Claire, WI & 9.3 & 6.7 & Frozen Pizza & 11.7 & 7.3 \\
\hline Grand Rapids, MI & 8.8 & 5.4 & Hotdogs & 13.6 & 7.4 \\
\hline Green Bay, WI & 8.5 & 5.3 & Household Cleaners & 9.0 & 6.7 \\
\hline Harrisburg/Scranton, PA & 9.7 & 7.5 & Laundry Detergent & 10.4 & 6.7 \\
\hline Hartford, CT & 10.7 & 7.2 & Margarine/Butter & 11.0 & 8.0 \\
\hline Houston, TX & 9.4 & 7.3 & Mayo & 11.5 & 7.7 \\
\hline Indianapolis, IN & 9.9 & 6.5 & Milk & 8.5 & 6.6 \\
\hline Kansas City, MO & 9.9 & 7.9 & Mustard/Ketchup & 9.9 & 7.5 \\
\hline Knoxville, TN & 7.7 & 4.9 & Paper Towels & 8.1 & 5.4 \\
\hline Los Angeles, CA & 11.9 & 9.0 & Peanut Butter & 8.8 & 6.4 \\
\hline Milwaukee, WI & 8.6 & 5.9 & Photo Supplies & 14.1 & 10.8 \\
\hline Minneapolis/St. Paul, MN & 7.1 & 4.1 & Razors & 9.7 & 7.5 \\
\hline Mississippi & 9.3 & 6.5 & Salty Snacks & 10.8 & 6.1 \\
\hline New England & 9.3 & 7.8 & Shampoo & 10.8 & 8.2 \\
\hline New Orleans, LA & 9.1 & 6.2 & Soup & 12.4 & 8.5 \\
\hline New York, NY & 12.7 & 9.5 & Spaghetti Sauce & 10.8 & 7.4 \\
\hline Oklahoma City, OK & 5.7 & 3.1 & Sugar Substitutes & 7.6 & 6.1 \\
\hline Omaha, NE & 9.3 & 6.9 & Toilet Tissues & 10.9 & 7.5 \\
\hline Peoria/Springfield, IL & 11.5 & 8.3 & Toothbrush & 12.7 & 9.7 \\
\hline Philadelphia, PA & 13.3 & 9.6 & Toothpaste & 11.7 & 8.0 \\
\hline Phoenix, AZ & 10.6 & 6.9 & Yogurt & 9.3 & 6.2 \\
\hline Pittsfield, MA & 10.1 & 6.1 & & & \\
\hline Portland, OR & 10.3 & 7.5 & & & \\
\hline Providence, RI & 7.5 & 3.9 & & & \\
\hline Raleigh/Durham, NC & 8.8 & 6.0 & & & \\
\hline Richmond/Norfolk, VA & 9.3 & 6.5 & & & \\
\hline Roanoke, VA & 8.7 & 6.1 & & & \\
\hline Sacramento, CA & 10.7 & 6.8 & & & \\
\hline Salt Lake City, UT & 8.1 & 5.0 & & & \\
\hline San Diego, CA & 11.7 & 8.1 & & & \\
\hline San Francisco, CA & 11.4 & 7.8 & & & \\
\hline Seattle/Tacoma, WA & 11.0 & 7.9 & & & \\
\hline South Carolina & 9.8 & 7.1 & & & \\
\hline Spokane, WA & 9.5 & 6.4 & & & \\
\hline St. Louis, MO & 8.9 & 5.7 & & & \\
\hline Syracuse, NY & 9.7 & 7.7 & & & \\
\hline Toledo, $\mathrm{OH}$ & 9.3 & 6.1 & & & \\
\hline Tulsa, OK & 7.4 & 4.7 & & & \\
\hline Washington, DC & 11.1 & 8.2 & & & \\
\hline West Texas/New Mexico & 11.0 & 8.0 & & & \\
\hline
\end{tabular}

Source: Author's calculations based on the IRI data.

Notes: This table shows estimates of price dispersion from Table 1 by market and product category. 


\section{B Spatial Heterogeneity and Dynamic Properties of Price Dispersion}

Conventional wisdom, engraved into a textbook treatment of the cost of inflation, holds that a higher inflation is also a more volatile one; thus, in models with a positive relationship between inflation and price dispersion, a higher dispersion should be a more volatile one, too. I find that in the data it is the opposite: as the level of price dispersion falls, its cross-sectional heterogeneity rises. To illustrate this point, I take price dispersion at the market level (the time average of the benchmark dispersion measure), $\bar{\sigma}_{m}=\sum_{t} \sigma_{m t} / T$, and then compute the heterogeneity of $\bar{\sigma}_{m}$ across markets (dispersion of dispersion). Table B1 reports the standard deviation of $\bar{\sigma}_{m}$ over $m$, the range (the difference between the markets with the highest and lowest dispersion), the 90-10 percentile spread, and the interquartile range (75-25 spread). Price dispersion in the market with the highest $\bar{\sigma}_{m}$ is 8.9 log points higher than in the market with the lowest $\bar{\sigma}_{m}$ (7.8 log points higher for regular prices). This spread increased from 7.8 to $10.8 \mathrm{log}$ points after the beginning of the Great Recession (from 6.9 to $9.3 \mathrm{log}$ points for regular prices). The other measures mostly support this finding, but the changes are less pronounced.

The high degree of the cross-sectional heterogeneity of price dispersion is not surprising since prices are more dispersed in larger markets; the increase in heterogeneity over time, however, is-since the level of price dispersion falls during the same period. To show how the level and variability of price dispersion evolve over time, I plot (Panels A and C of Figure B1) market-level dispersion in month $t, \bar{\sigma}_{t}=\sum_{m} \sigma_{m t} / M$, against its variability across markets, $\Sigma_{t}=\left\{\sum_{m}\left(\sigma_{m t}-\bar{\sigma}_{t}\right)^{2} /(M-1)\right\}^{1 / 2}$. Until 2007, the level and variability had been rising; then, its level decreased by approximately 1 log point, while heterogeneity increased. The two have been moving in the opposite directions since then. This pattern is similar in posted and regular prices.

The negative relationship between the level of price dispersion and its time volatility also holds for individual markets: markets with a higher average price dispersion have a lower dispersion volatility over time. This can be seen from a plot (Panels B and D of Figure B1) of $\bar{\sigma}_{m}$ against $\Sigma_{m}=\left\{\sum_{m}\left(\log \sigma_{m t}-\overline{\log \sigma}_{m}\right)^{2} /\right.$ $(T-1)\}^{1 / 2}$, the standard deviation of $\log \sigma_{m t}$ over $t .^{1}$ To enhance readability, only large markets are labeled. Besides the main point of this plot, a few other things are noticeable. First, markets with the highest dispersion are, predictably, big markets (New York, Philadelphia, Los Angeles). Second, markets with the lowest dispersion are not necessarily the smallest markets (Minneapolis/St. Paul and Atlanta are not small). Again, posted and regular prices look similar.

The analysis in this section should be treated as purely descriptive. There are many factors other than inflation that may affect the level and variability of price dispersion (for example, the pattern of M\&A). Smaller markets are represented by fewer stores in the data; thus, the measurement error may be larger. Hence, withinmarket variation-examined in the next section-should be a more reliable source of identification than the cross-sectional variation. Even so, just by looking at the cross-sectional and aggregate properties of price dispersion, one can already find significant discrepancies between the data and models.

Table B1. Heterogeneity of Average Price Dispersion across Markets, log points

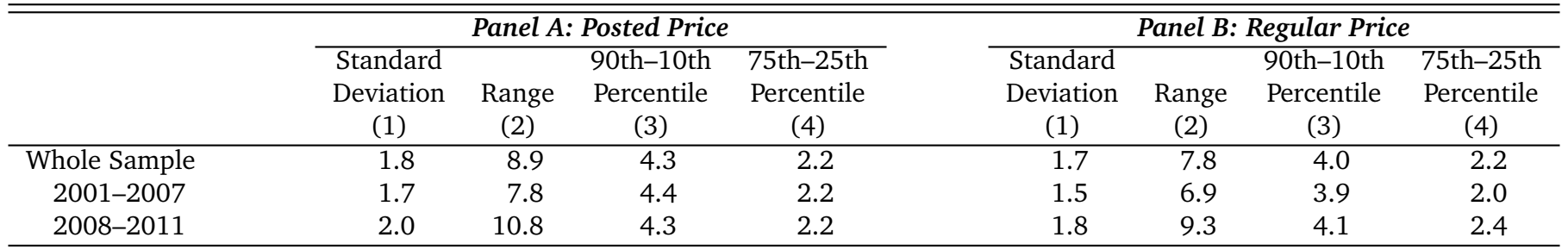

Source: Author's calculations based on the IRI data.

Notes: The table reports measures of cross-market variability of price dispersion. Market-level price dispersion is measured by the average weekly standard deviation of log prices. Panel A is for posted (observed) prices and Panel B is for regular prices (that is, excluding temporary price reductions). Column (1) reports the standard deviation of price dispersion across markets, column (2) the difference between the highest and the lowest dispersion market, column (3) the difference between the 90th and 10th percentile of the distribution across markets, and column (4) the interquartile range.

\footnotetext{
${ }^{1}$ Markets with a higher average price dispersion may have a higher time volatility mechanically, due to the linearity of a standard deviation. To express volatility in real terms, I compute the standard deviation of $\log$ dispersion. In the previous cases, the time variation for aggregate measures was small; thus, there was no need for the log transformation.
} 

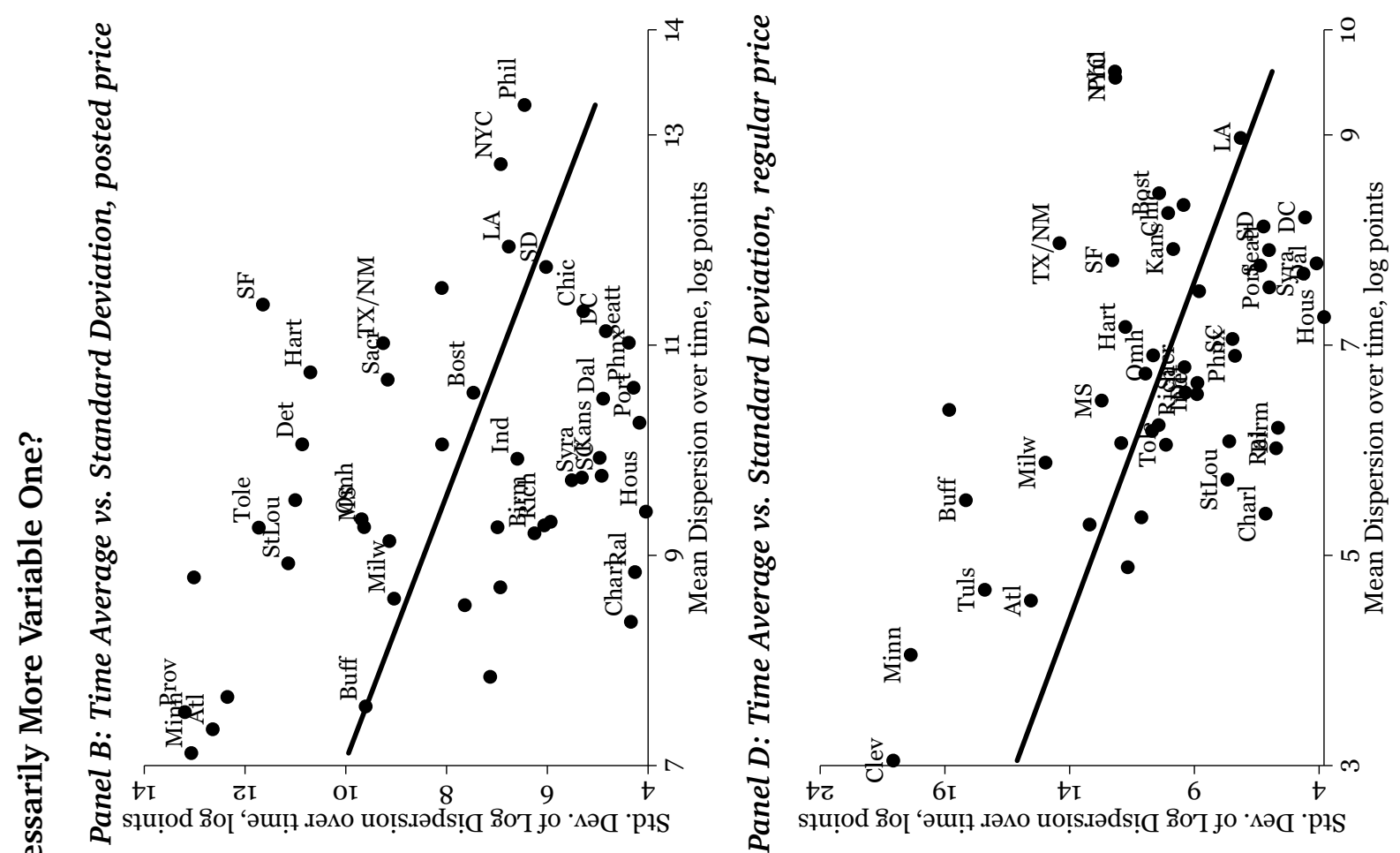

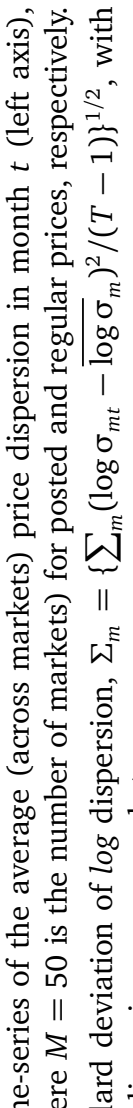

岂芯艺

辽要

폻

기 정

结要

สิ

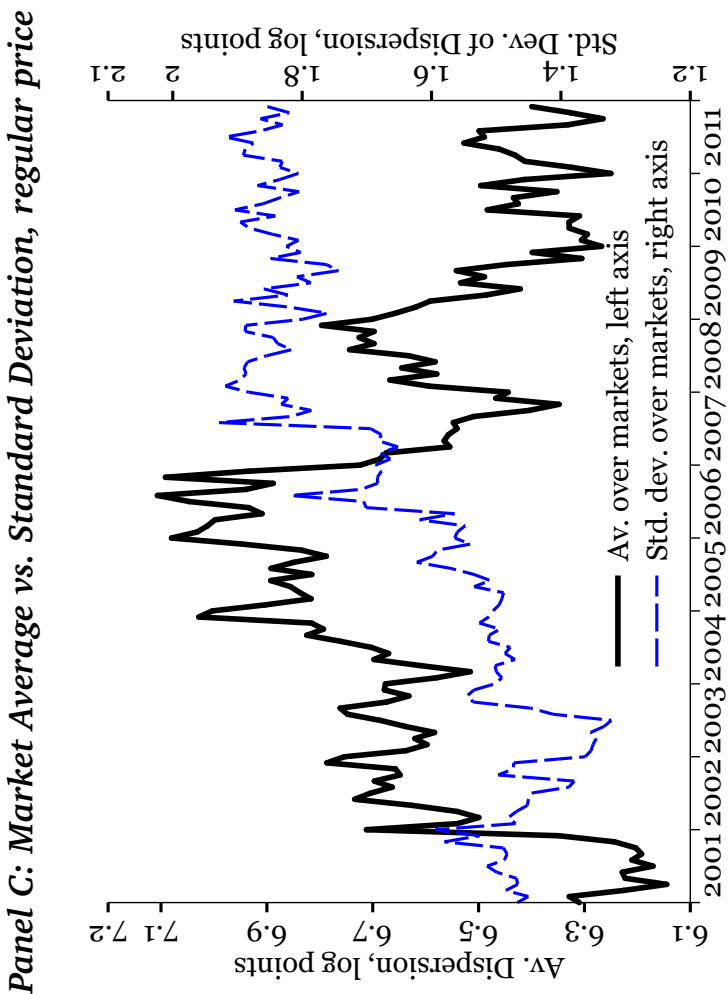

$\varangle 10^{2} b^{2}$

先

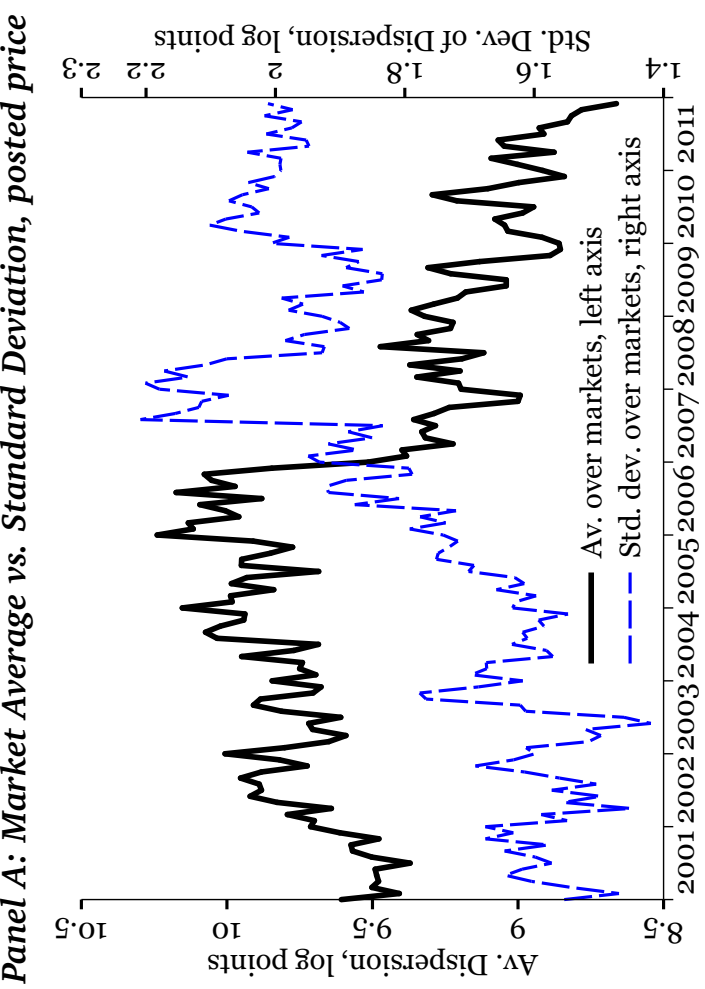

可密

ब $b^{2} \|$

+[ $\sqrt[5]{10} \approx$

亖

㱏芯

"ซิ่)

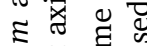

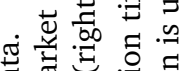

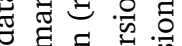

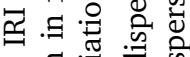

을 용

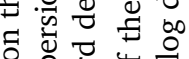

○昰出

च تٓ

敋

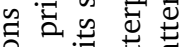

곰듀

政

ช 300

की

을 है

ये ज्ञ

¿ّं

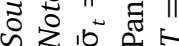




\section{Comovement of Price Dispersion and Inflation at the Aggregate Level}

In the main text, I estimate the relationship between inflation and price dispersion at the disaggregated level of markets and categories. This is done for two statistical reasons, among others: First, it allows me to expand the cross-sectional dimension and increase the number of observations. This is important because the data cover only 11 years of observations, while there is a need to control for aggregate trends (by including time fixed effects) and to allow for a complex correlation structure of residuals. Second, it allows me exploit the crossmarket and cross-category variation in inflation rates, since we do not observe much of that at the aggregate level in the 2000s.

Although multisector aggregate models often produce a relationship between sectoral inflation and price dispersion that is similar to that relationship at the aggregate level, it is important to understand whether the comovement found in the data is driven by the changes in relative prices or by the changes in the overall price level. To show that the main results do not come entirely from the variation in relative prices, I estimate the baseline specification at the aggregate level. In particular, I first aggregate inflation and price dispersion to the market level, $\sigma_{m t}$ and $\pi_{m t}$. Then, I compute the averages over markets using (i) equal weights and (ii) weights based on total sales in a market and year. Predictably, it is difficult to tease out significant estimates from time-series regressions with 131 observations; however, the pattern is by and large consistent with the results obtained from the disaggregated data. Table $\mathrm{C} 1$ reports the comovement coefficient for raw averages (Panel A) and for weighted averages (Panel B). The standard errors are robust Newey-West. The columns report the results for price dispersion across stores, across chains, and net of seller fixed effects, respectively. ${ }^{1}$ For posted prices, the comovement coefficient is -0.075 for the raw averages and -0.022 for the weighted averages. Although the standard error of the latter estimate is large, the magnitude roughly coincides with the benchmark estimate. ${ }^{2}$ For regular prices, the comovement coefficient is only significant in the weightedaverage regression and is equal to 0.057 ( 0.026 in the disaggregated data). The estimates are more precise for net dispersion, similar to the benchmark estimates.

If the aggregate results were interpreted per se, the relationship between inflation and price dispersion would be difficult to pin down, since the data do not allow for precise estimation of the aggregate comovement due to relatively short time-series. However, in combination with the baseline results obtained on the disaggregated level, the estimates presented here suggest that the relationship between price dispersion and inflation within a market-category is closely related to aggregate fluctuations, which is consistent with the models.

Table C1. Comovement of Price Dispersion and Inflation at the Aggregate Level

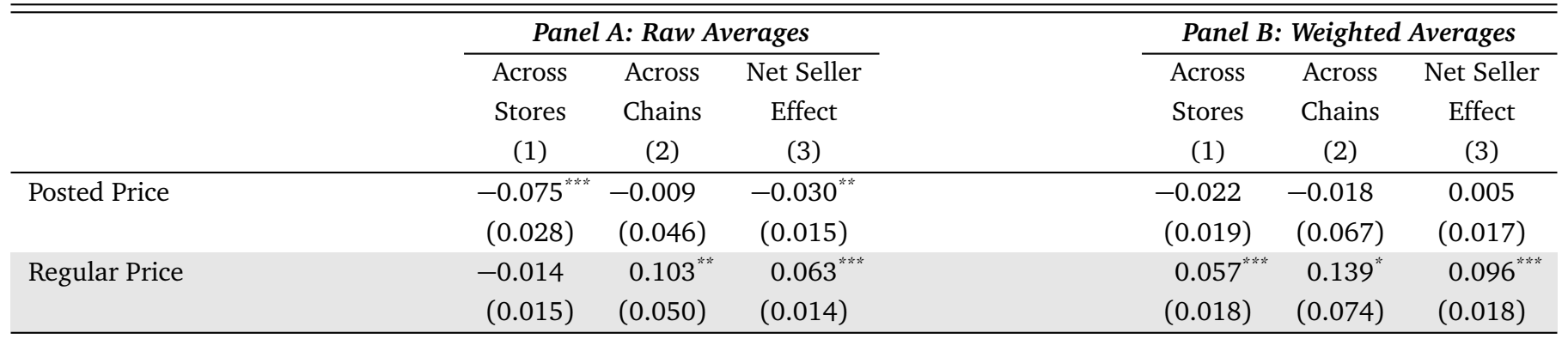

Source: Author's calculations based on the IRI data.

Notes: Panel A aggregates price dispersion and inflation by computing raw averages over markets. Panel B uses weights based on the annual total sales in a given market. Columns (1)-(3) use cross-store, cross-chain, and net-of-seller-specific-effect measures of price dispersion, respectively. Estimation sample covers 2001-2011. Number of observations $N=131$. The data are seasonally adjusted using the X12-ARIMA procedure from the U.S. Census. Newey-West standard errors with serial correlation of up to three lags are in parentheses.

$*, * * * * *$ denote 10,5 , and 1 percent significance level, respectively

\footnotetext{
${ }^{1}$ See Section 2.3 for more details.

${ }^{2}$ However, if instead robust standard errors are used, it becomes significant at the 5 percent level. Ideally, to rely on Newey-West estimates, one would want to have a longer time-series.
} 


\section{Disaggregated Inflation Rates}

Let $T S_{i s m \tau}$ and $T Q_{i s m \tau}$ be total sales and quantities, respectively, for good $i$, store $s$, market $m$, and week $\tau$. The unit price of the good in month $t$ is then computed as

$$
P_{i s m t}=\frac{\sum_{\tau \in \mathscr{M}^{t}} T S_{i s m \tau}}{\sum_{\tau \in \mathscr{M}^{t}} T Q_{i s m \tau}},
$$

with $\mathscr{M}^{t}$ being a set of weeks in month $t$. This measure represents the average effective price that consumers paid for a good in a given store within a month. I then compute a store-level price change for a given good as

$$
\pi_{i s m t}=\log P_{i s m t}-\log P_{i s m, t-1} \text {. }
$$

Next, I aggregate these price changes into the inflation rate at the market-category level:

$$
\pi_{m c t}=\sum_{i \in \mathscr{G} m c t} \sum_{s \in \mathscr{S}^{m c t}} \omega_{i s m t} \pi_{i s m t}
$$

where $\omega_{i s m t}$ are annual weights (that is, fixed within each year) for good $i$ and store $s, \mathscr{G}^{m c t}$ is a set of goods, and $\mathscr{S}^{m c t}$ is a set of stores in a given market $m$ and goods category $c$. I compute both direct and multiplicative weights. Direct weights, $\omega_{i s m t}^{\mathrm{dir}}$, are based on total annual sales of a good in a store:

$$
\omega_{i s m t}^{\mathrm{dir} .}=\frac{\sum_{\tau \in \mathscr{Y}^{t}} T S_{i s m \tau}}{\sum_{\tau \in \mathscr{Y}^{t}} \sum_{i \in \mathscr{G}^{m c t}} \sum_{s \in \mathscr{S}^{m c t}} T S_{i s m \tau}},
$$

with $\mathscr{Y}^{t}$ being a set of months in the same year as month $t$. Alternatively, multiplicative weights, $\omega_{i s m t}^{\text {mult. }}$ are based on the product of goods and stores weights:

$$
\omega_{i s m t}^{\text {mult. }}=\underbrace{\frac{\sum_{\tau \in \mathscr{Y}^{t}} \sum_{s \in \mathscr{S}^{m c t}} T S_{i s m \tau}}{\sum_{\tau \in \mathscr{Y}^{t}} \sum_{i \in \mathscr{G}^{m c t}} \sum_{s \in \mathscr{S}^{m c t}} T S_{i s m \tau}}}_{\text {product weights }} \cdot \underbrace{\frac{\sum_{\tau \in \mathscr{Y}^{t}} \sum_{i \in \mathscr{G}^{m c t}} T S_{i s m \tau}}{\sum_{\tau \in \mathscr{Y}^{t}} \sum_{i \in \mathscr{G}^{m c t}} \sum_{s \in \mathscr{S}^{m c t}} T S_{i s m \tau}}}_{\text {store weights }} .
$$

Inflation rates obtained using these weights are treated as a benchmark; however, there is little difference in the main results when direct weights are used instead. As the paper's main part discusses, using weights common across the markets does not affect the results either. Average trend inflation obtained using this method tends to be within 1 percentage point of trend inflation for food and beverages in the BLS data. 


\section{E Sensitivity Analysis of the Empirical Results}

I show that the relationship between price dispersion and inflation is not sensitive to various assumptions in the main text. Namely, I check robustness to the following: (i) seasonal adjustment, (ii) cross-sectional and time aggregation, and (iii) the number of stores used to compute dispersion.

Since the data exhibit seasonal patterns, the baseline estimates are based on the seasonally adjusted data. The adjustment is done using the U.S. Census X12-ARIMA algorithm. This algorithm accounts for seasonal patterns that are responsible for high-frequency fluctuations (within a year), calendar effects such as trading days and moving holidays, and extreme values (outliers), and it applies one-sided filters at each end of a series. To make sure that this procedure does not lead to extra smoothness in the adjusted series, I compare the estimates based on the X12-ARIMA filter (baseline), on the 12-month moving average filter, and those based on the untransformed data. ${ }^{1}$ The MA(12) filter is in the spirit of X12-ARIMA, but it is more parsimonious and transparent. In particular, it implies the following transformation:

$$
x_{t}^{\mathrm{ma}}=\frac{\sum_{i=0}^{11} x_{t-i}}{12}
$$

where $x_{t}=\left\{\sigma_{m c t}, \pi_{m c t}\right\}$, and $x_{t}^{\mathrm{ma}}$ are floating annual averages. This filter implies that $\Delta x_{t}^{\mathrm{ma}}=\left(x_{t}-x_{t-12}\right) / 12$; hence, first differences represent a change relative to the same month of the previous year, thereby removing a seasonal component. As Panel A of Table E1 shows, the choice of the seasonal-adjustment filter is irrelevant for the theoretical implications presented in the paper. Using the MA(12) filter leads to an increase in the coefficients' absolute value relative to the baseline, while using no filter leads to a smaller (than in the baseline) coefficient for regular prices, but not for posted prices.

To compute the measures of inflation and price dispersion at the market-category level, I aggregate price dispersion over UPCs and inflation over UPCs and stores. For the baseline case I use market-specific weights based on annual total sales. Specifically, let $(i, s)$ index UPC-stores in category $c$, and $x_{i s m t}$ be a disaggregated measure for market $m$ and month $t$. Then, direct annual market-specific weights $\left(\omega_{i s m t}\right)$ are defined as follows:

$$
\omega_{i s m t}^{\text {direct,market }}=\frac{T S_{i s m \tau}}{\sum_{i s \text { in } c} T S_{i s m \tau}}
$$

where $T S_{i s m \tau}$ are total sales of product $i$ in store $s$, market $m$, and year $\tau$. Alternatively, I compute multiplicative weights as a product of UPC- and store-based weights: $\omega_{i s m t}^{\text {mult.,market }}=\omega_{i m t}^{\mathrm{UPC}} \cdot \omega_{s m t}^{\text {store }}$, with

$$
\begin{aligned}
\omega_{i m t}^{\mathrm{UPC}} & =\frac{\sum_{s} T S_{i s m \tau}}{\sum_{i \text { in } c} \sum_{s} T S_{i s m \tau}}, \\
\omega_{\text {smt }}^{\text {store }} & =\frac{\sum_{i} T S_{i s m \tau}}{\sum_{s} \sum_{i \text { in } c} T S_{i s m \tau}} .
\end{aligned}
$$

I also aggregate the variables using common weights (the same weights across markets):

$$
\omega_{i s t}^{\text {direct,common }}=\frac{\sum_{m} T S_{i s m \tau}}{\sum_{i s \text { in } c} \sum_{m} T S_{i s m \tau}} .
$$

The results are not sensitive to the choice of cross-sectional aggregation weights (Panels B1 and B2 of Table E1). Moreover, even if I aggregate the variables based on equal weights, the results are qualitatively-and also quantitatively, for regular prices-similar to the baseline case.

In the baseline specification, price dispersion and inflation are aggregated to a monthly frequency in two

\footnotetext{
${ }^{1}$ As I include monthly dummies in the baseline specification, the results based on the untransformed data account for seasonal patterns trivially.
} 


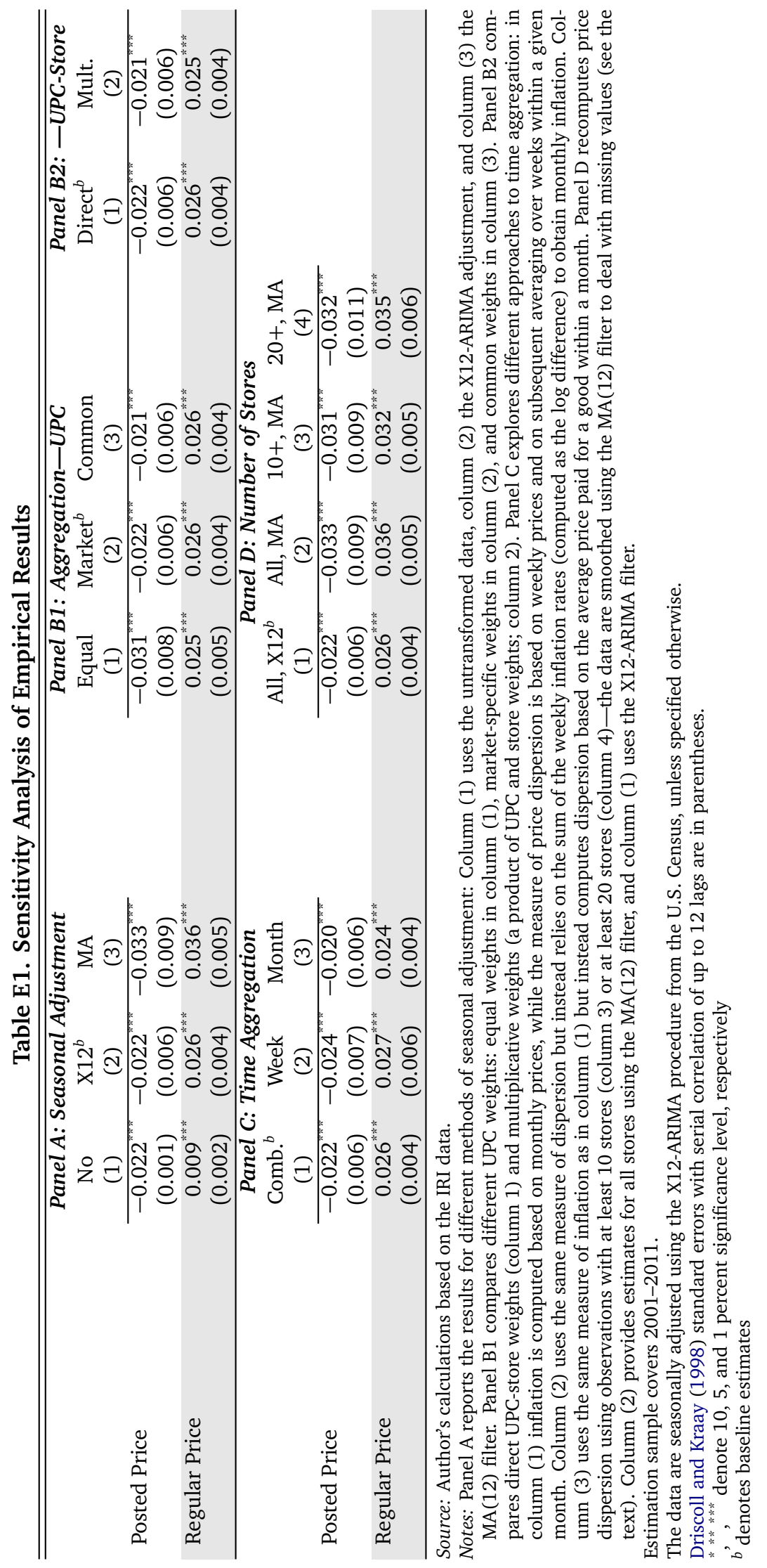


different ways. First, from the economic point of view, one can compute each measure at a weekly frequency and then take the average (for dispersion) or sum (for inflation) over weeks. Second, due to missing observations in the weekly data, it is possible to get statistically more accurate results if the raw data are aggregated to a monthly frequency before inflation and dispersion are computed. I apply the former method to aggregate dispersion because it is essential to compare prices across stores within narrow time intervals-otherwise dispersion might be due to the timing of purchase-and I apply the latter method to compute inflation because it provides a more accurate measure of monthly changes in the disaggregated price level. The choice of time aggregation has no meaningful effect on the results: Panel C of Table E1 reproduces the benchmark estimates in column (1) and then reports the estimates from the main specification for both variables aggregated using the first method (column 2) or the second method (column 3). There is a negligible difference in the coefficients: less than $0.002 \log$ points. This result suggests that it is unlikely that missing values play an important role.

Some markets in the data are represented by a small number of stores, which may lead to a large sampling error in the estimates of price dispersion. Moreover, large markets are characterized by a large number of stores, and also tend to have high price dispersion. ${ }^{2}$ I show that the estimates based on the observations with a large number of stores are similar to the baseline. I compute the amount of price dispersion for goods with at least 10 or 20 stores in a given market and week. This procedure has two effects: (1) some markets are excluded entirely; and (2) for some other markets, it introduces time-series gaps. Because of the latter reason, I cannot use the X12-ARIMA seasonal-adjustment procedure, which does not allow for time-series gaps. Instead, I resort to the MA(12) filter. The first two columns of Panel D of Table E1 reproduce the baseline results for the X12-ARIMA and MA(12) seasonally adjusted data. Columns (3) and (4) report the results for observations with at least 10 and at least 20 stores, respectively, both obtained from the MA(12)-filtered data. These estimates are very close to those in column (2).

\footnotetext{
${ }^{2}$ For example, the data contain 152 delivery stores in New York, NY, and only nine in Eau Claire, WI. Predictably, the dispersion of prices is higher in New York: 12.7 vs. 9.3 log points.
} 


\section{F Additional Empirical Results}

\section{Alternative Structural Specification}

If Equation (4) is an accurate representation of the data-generating process, one can iterate backward to obtain the following specification:

$$
\sigma_{m c, t}^{2}=\beta_{1} \pi_{m c, t}^{2}-\beta_{2} \pi_{m c, t}+\Phi_{1}(L) \pi_{m c, t-1}+\Phi_{2}(L) \pi_{m c, t-1}^{2}+\gamma_{m c}+\tau_{t}+\varepsilon_{m c, t}
$$

where $\Phi_{i}(L)$ is a lag polynomial of an arbitrarily high order, $i=\{1,2\}$. This is to say that the lag of price dispersion can be approximated by sufficiently many lags of the level and the squared term of inflation. I show the estimates of this specification in column (2) of Table F1 and contrast them with the baseline estimates in column (1). For posted prices, the coefficient on squared inflation is negative and larger in magnitude, suggesting that a true data-generating process is different from Equation (4). For regular prices, the coefficients retain their sign but increase in absolute value, moving further from the predictions of the structural specification.

Table F1. Structural Specification with Inflation Lags as Proxy for Lag Dispersion

\begin{tabular}{lccccc}
\hline \hline & \multicolumn{2}{c}{ Panel A: Posted Prices } & & \multicolumn{2}{c}{ Panel B: Regular Prices } \\
\cline { 2 - 3 } & Baseline & Lags & & Baseline & Lags \\
& $(1)$ & $(2)$ & & $(1)$ & $(2)$ \\
\hline Inflation & $-0.004^{* * * *}$ & 0.008 & & $0.005^{* * * *}$ & $0.025^{* * * *}$ \\
& $(0.001)$ & $(0.005)$ & & $(0.001)$ & $(0.003)$ \\
Inflation Squared & $0.008^{*}$ & $-0.027^{* * *}$ & $-0.010^{* * *}$ & $-0.045^{* * *}$ \\
& $(0.004)$ & $(0.009)$ & $(0.005)$ & $(0.006)$ \\
Lag Price Dispersion & $0.542^{* * * *}$ & & $0.499^{* * * *}$ & $(0.044)$ & 0.02 \\
$R^{2}$, within & $(0.044)$ & & 0.26 & 0.02 \\
$N$ & 0.30 & 0.03 & 185,280 & 183,736 \\
\hline
\end{tabular}

Source: Author's calculations based on the IRI data.

Notes: This table compares the baseline structural specification from the Calvo model (column 1, or column 3 of Table 2) and the alternative specification that uses inflation lags as a proxy for lag price dispersion (column 2). " ,, , $^{* * *}$ denote 10,5 , and 1 percent significance level, respectively.

\section{Fixed Effects}

I examine how market, category, and time fixed effects each affect the comovement of price dispersion and inflation, and how much of the variation in price dispersion they can explain (Table F2). The baseline specification controls for market-category and time fixed effects, and its results are reproduced in column (8). Column (1) reports the results when neither cross-sectional nor time fixed effects are included. In columns (2)-(4), I drop time fixed effects but keep cross-sectional ones: market only, category only, and market-category, respectively. Columns (5)-(7) add time fixed effects to the specifications in (2)-(4). Panel A reports the comovement coefficient $\beta$ from the reduced-form specification, while Panel B shows the amount of variation in price dispersion explained by the econometric model (measured with $R^{2}$ ). For posted prices, market fixed effects are the most important; they explain 37 percent of the variation in price dispersion and are responsible for most of the coefficient change relative to the case with no fixed effects. For regular prices, category fixed effects are more important, explaining 34 percent of the variation. However, the effect of category fixed effects on the comovement coefficient is only slightly greater than that of market fixed effects. Time fixed effects do not affect the comovement coefficient much and explain only a tiny share of the variation in dispersion. 
Table F2. Fixed Effects and the Comovement Estimates

\begin{tabular}{|c|c|c|c|c|c|c|c|c|}
\hline $\begin{array}{l}\text { Fixed } \\
\text { Effects: }\end{array}$ & $\begin{array}{l}\text { No } \\
(1)\end{array}$ & $\begin{array}{c}\text { Market (M) } \\
(2)\end{array}$ & $\begin{array}{c}\text { Category }(\mathrm{C}) \\
(3) \\
\end{array}$ & $\begin{array}{c}\text { M-C } \\
(4)\end{array}$ & $\begin{array}{c}\text { Time }(\mathrm{T}) \\
(5)\end{array}$ & $\begin{array}{l}\text { M, T } \\
(6)\end{array}$ & $\begin{array}{l}\text { C, T } \\
(7)\end{array}$ & $\begin{array}{c}\text { M-C, } \mathrm{T}^{b} \\
(8)\end{array}$ \\
\hline \multicolumn{9}{|c|}{ Panel A: Comovement Coefficient } \\
\hline Regular Price & $\begin{array}{l}0.050^{* * * *} \\
(0.009)\end{array}$ & $\begin{array}{l}0.047^{* * * k} \\
(0.006)\end{array}$ & $\begin{array}{l}0.042^{* * * *} \\
(0.008)\end{array}$ & $\begin{array}{l}0.029^{* * *} \\
(0.004)\end{array}$ & $\begin{array}{l}0.050^{* * *} \\
(0.009)\end{array}$ & $\begin{array}{l}0.047^{* * * *} \\
(0.007)\end{array}$ & $\begin{array}{l}0.042^{* * * *} \\
(0.008)\end{array}$ & $\begin{array}{l}0.026^{* * * *} \\
(0.004)\end{array}$ \\
\hline Posted Price & 0.01 & 0.37 & 0.28 & 0.77 & 0.01 & 0.38 & 0.29 & 0.78 \\
\hline Regular Price & 0.01 & 0.21 & 0.34 & 0.70 & 0.01 & 0.22 & 0.35 & 0.70 \\
\hline
\end{tabular}

Source: Author's calculations based on the IRI data.

Notes: Estimation sample covers 2001-2011. Number of observations $N=202,788$ for posted prices and $N=202$, 264 for regular prices.

The data are seasonally adjusted using the X12-ARIMA procedure developed by and available from the U.S. Census.

Driscoll and Kraay (1998) standard errors are in parentheses. Serial correlation of up to 12 lags is allowed.

$* * * * * *$ denote 10,5 , and 1 percent significance level, respectively; ${ }^{b}$ denotes baseline estimates

\section{Time-Average Inflation and Price Dispersion}

The main specification is based on the comovement of inflation and price dispersion within markets and product categories. I also examine whether a similar relationship arises between markets and categories. Since "between" regressions are based on averaging over 11 years of data, one can roughly think of this exercise as measuring a steady-state relationship between the variables. Remarkably, in sticky-price models, the steadystate relationship between inflation and price dispersion is often similar to that in the actual variables. For example, in the Calvo model, it can be approximated by a simple linear relationship:

$$
\bar{\sigma}^{2} \simeq \frac{\alpha}{(1-\alpha)^{2}} \bar{\pi}^{2}
$$

where $\bar{\sigma}$ and $\bar{\pi}$ are steady-state price dispersion and inflation, respectively, and $(1-\alpha)$ is the frequency of price adjustment. The structural specification in turn can be rewritten as

$$
\begin{aligned}
& \bar{\sigma}^{2}=\frac{\beta_{1}}{1-\alpha} \bar{\pi}^{2}-\frac{\beta_{2}}{1-\alpha} \bar{\pi}+\varepsilon, \text { or } \\
& \bar{\sigma}^{2}=\gamma_{1} \bar{\pi}^{2}-\gamma_{2} \bar{\pi}+\varepsilon,
\end{aligned}
$$

with $\gamma_{1}, \gamma_{2}>0$. The estimates shown in Table F3 establish two results: (1) a positive relationship between inflation and price dispersion for regular prices and a negative relationship for posted prices also holds between markets and categories; and (2) the Calvo model explains the steady-state behavior of price dispersion and inflation poorly.

Table F3. Comovement of Time-Average Inflation and Price Dispersion

\begin{tabular}{lccccccc}
\hline \hline \multirow{2}{*}{ Price Dispersion } & \multicolumn{3}{c}{ Panel A: Posted Prices } & & \multicolumn{3}{c}{ Panel B: Regular Prices } \\
\cline { 2 - 4 } \cline { 7 - 8 } & Level & Squared & Squared & & Level & Squared & Squared \\
& $(1)$ & $(2)$ & $(3)$ & & $(1)$ & $(2)$ & $(3)$ \\
\hline Inflation & $-0.332^{* * * *}$ & & $-0.026^{* * *}$ & & $0.179^{* * * *}$ & & $0.080^{* * * *}$ \\
& $(0.055)$ & & $(0.013)$ & & $(0.033)$ & & $(0.009)$ \\
Inflation Squared & & $-0.437^{* * * *}$ & $-0.378^{* * * *}$ & & & 0.005 & $-0.299^{* * * *}$ \\
& & $(0.053)$ & $(0.061)$ & & & $(0.024)$ & $(0.041)$ \\
$R^{2}$ & 0.02 & 0.04 & 0.04 & & 0.02 & 0.00 & 0.05 \\
$N$ & 1,548 & 1,548 & 1,548 & & 1,544 & 1,544 & 1,544 \\
\hline
\end{tabular}

Source: Author's calculations based on the IRI data.

Notes: The table reports coefficients from regressing the time average of price dispersion on the time average of inflation. ******* denote 10,5 , and 1 percent significance level, respectively. 


\section{Positive and Negative Inflation}

In the Calvo model, the volatility of inflation, not the direction of price changes per se, is the source of price dispersion. I test empirically whether increases and decreases in the price level have the same effect on price dispersion. I split the sample into the two subsamples of positive and negative inflation. If the data-generating process is Calvo, the coefficients obtained from the two subsamples should have the same size and opposite sign. The results in columns (2) and (3) of Table F4 suggest that this is not the case. For posted prices, the coefficients are negative and similar to each other in size. For regular prices, the effects of positive and negative inflation on inflation are closer to those in the Calvo model.

Table F4. Comparing the Comovement for Positive and Negative Inflation

\begin{tabular}{lcccc}
\hline \hline & Inflation $^{b}$ & Positive Inf- & Negative Inf- & Absolute \\
& Level, $\pi$ & lation, $\pi>0$ & lation, $\pi<0$ & Value, $|\pi|$ \\
& $(1)$ & $(2)$ & $(3)$ & $(4)$ \\
\hline Posted Price & $-0.022^{* * *}$ & $-0.019^{* * *}$ & $-0.023^{* *}$ & $-0.010^{* *}$ \\
& $(0.008)$ & $(0.007)$ & $(0.012)$ & $(0.004)$ \\
& {$[202,788]$} & {$[119,490]$} & {$[83,295]$} & {$[202,788]$} \\
Regular Price & $0.026^{* * *}$ & $0.029^{* * *}$ & -0.016 & $0.029^{* * *}$ \\
& $(0.004)$ & $(0.004)$ & $(0.012)$ & $(0.004)$ \\
& {$[202,264]$} & {$[191,191]$} & {$[11,073]$} & {$[202,264]$} \\
\hline
\end{tabular}

Source: Author's calculations based on the IRI data.

Notes: Each column presents coefficients from regressions of price dispersion on inflation for different samples or variables. Column (1) uses the level of inflation as in the baseline specification. Columns (2) and (3) look at subsamples with positive and negative inflation, respectively. For the latter case, the level of inflation (negative values) is used. Column (4) uses the absolute value of inflation.

Driscoll and Kraay (1998) standard errors are in parentheses. Serial correlation of up to 12 lags is allowed.

Estimation sample covers 2001-2011. Number of observations is in brackets.

The data are seasonally adjusted using the X12-ARIMA procedure from the U.S. Census.

$*, *, * * *$ denote 10,5 , and 1 percent significance level, respectively; ${ }^{b}$ denotes baseline estimates 


\section{G Dynamic Relationship between Inflation and Price Dispersion}

I examine whether the relationship between inflation and price dispersion is static or dynamic, potentially another criterion to distinguish between various macro models. In particular, in models with time-dependent price adjustment (such as Calvo 1983), price dispersion is persistent; therefore, a shock to inflation has a long-lasting effect on price dispersion. In state-dependent models (Dotsey, King, and Wolman 1999, Golosov and Lucas 2007), this effect decays fast, since a large inflation shock in the future may completely offset the effect of a smaller shock in the past. In search models (Benabou 1988, 1992, Head et al. 2012), the effect is completely static: one variable affects the other only within the same period. In uncertain and sequential trade (UST) models (Eden 1994, Williamson 1996), monetary shocks do not lead to any relationship between inflation and price dispersion, which is inconsistent with the within-period comovement found in the data. Demand shocks affect price dispersion only contemporaneously, a result that also holds in search models.

To document whether the relationship between the two variables is static or dynamic (without making any structural inference), I estimate the effect on price dispersion over time of a change in inflation that cannot be predicted based on the history of the two variables. I rely on the direct projections approach (Jordà 2005, Stock and Watson 2007), a method that has a number of advantages over using vector autoregression (VAR). First, it is parsimonious and requires only estimating a series of single linear equations. Second, it can be applied to longitudinal data with a large number of panels. ${ }^{1}$ Finally, it simplifies the estimation of standard errors when the error term is correlated across time and product categories (for instance, one can use the Driscoll and Kraay 1998 approach). Essentially, the method is equivalent to obtaining the impulse-response function from a reduced-form bivariate VAR.

I estimate the following specification:

$$
\sigma_{m c, t+h}=\beta_{h} \pi_{m c, t}+\gamma_{m c}+\tau_{t}+\Psi_{11}^{\sigma}(L) \sigma_{m c, t-1}+\Psi_{11}^{\pi}(L) \pi_{m c, t-1}+\varepsilon_{m c, t+h},
$$

where $\Psi_{11}^{x}(L)=\sum_{i=0}^{11} \psi_{i}^{x} L^{i}(1-L)$ is the lag polynomial of order 11 applied to the first-difference of variable $x, x=\{\sigma, \pi\}$. This specification requires estimating a separate linear regression at each horizon $h$. Coefficient $\beta_{h}$ can be interpreted as a response of price dispersion in a given market and category to an unpredicted (by the lags of $\pi$ and $\sigma$ ) change in inflation $h$ periods after. ${ }^{2}$ Note that $\beta_{0}$ corresponds to the slope reported in column (7) of Table 2.

The impulse responses obtained from Equation (G1) and plotted in Figure G1 suggest a strong dynamic relationship between inflation and price dispersion. This finding supports the models of time-dependent price adjustment; it is only partly consistent with state-dependent models and is inconsistent with search and UST models. For posted prices, a change in inflation is associated with a negative response of price dispersion for about a year: the magnitude falls (in absolute value) from -0.043 on impact to -0.031 at the six-month horizon. For regular prices, the effect is significant (and positive) for six months. This discrepancy in the longevity of inflation shocks' effect is partly due to wider confidence bands; for regular prices the magnitude falls from 0.052 on impact to 0.032 at the six-month horizon, which is still a quantitatively large estimate.

\footnotetext{
${ }^{1}$ For an example and application of a panel VAR routine, see Love and Zicchino (2006).

${ }^{2}$ Previous studies often distinguish between the effect of perfectly anticipated inflation and that of inflation innovations (Lach and Tsiddon 1992, Reinsdorf 1994). In light of this literature, $\beta_{h}$ can be loosely viewed as an effect of inflation innovations on price dispersion. However, as the identification of inflation shocks requires a structural model—and potentially, there is some information beyond the lags of inflation and price dispersion that can be used to forecast inflation-I adhere to a softer view that $\beta_{h}$ is a dynamic analog of the intraperiod comovement of the two variables.
} 


\section{Figure G1. Response of Price Dispersion to Unforecasted Change in Inflation}

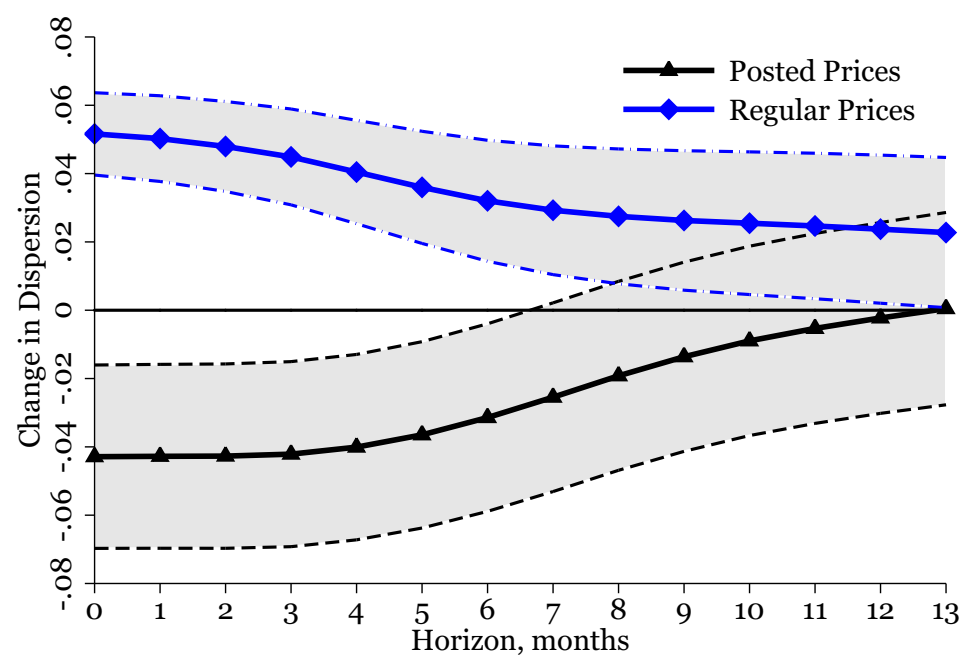

Source: Author's calculations based on the IRI data.

Notes: Solid lines show the response of the average weekly price dispersion, in log points, in a given market and product category to a corresponding one-log-point increase in the annualized monthly disaggregated inflation rate that cannot be forecasted with sufficiently long series of inflation and price dispersion. Estimation is based on the direct projections approach described in Equation (G1). The shaded area between dashed lines covers two Driscoll and Kraay (1998) standard errors (from each side) around the estimated response. 


\section{H Calvo Model and the Data: Structural Specification}

Since the Calvo model gives rise to a structural relationship between price dispersion and inflation, I show that this structural relationship is also inconsistent with the data. I estimate the analog of Equation (4) for the simulated data:

$$
\sigma_{t}^{2}=\alpha \sigma_{t-12}^{2}+\beta_{1} \pi_{t}^{2}-\beta_{2} \pi_{t}+\gamma+\varepsilon_{m c, t},
$$

where $\sigma_{t}^{2}$ is the variance of $\log$ prices simulated in the model, and $\pi_{t}$ is simulated inflation. To account for filtering, I use $\sigma_{t-12}^{2}$ as the lag of price dispersion.

The model and the data disagree along several dimensions (Table H1). First, in the model, price dispersion is too persistent. This implies that, in order to match the data, the Calvo model needs a higher degree of price flexibility. Second, the comovement is mostly driven by the linear term, supporting the reduced-form specification used in the main text. Finally, the model predicts a positive comovement; in the data, it is positive only for regular prices. And even for regular prices, the degree of the comovement in the Calvo model is much stronger than in the data.

Table H1. Calvo Model vs. Data: Structural Specification

\begin{tabular}{|c|c|c|c|c|c|}
\hline & \multicolumn{3}{|c|}{ Model } & \multicolumn{2}{|c|}{ Data } \\
\hline & $\begin{array}{l}\text { Monetary } \\
\text { (1) }\end{array}$ & $\begin{array}{l}\text { TFP } \\
(2)\end{array}$ & $\begin{array}{c}\text { Both Shocks } \\
\text { (3) }\end{array}$ & $\begin{array}{c}\text { Posted Prices } \\
\text { (4) }\end{array}$ & $\begin{array}{c}\text { Regular Prices } \\
\text { (5) }\end{array}$ \\
\hline Lag Price Dispersion & 0.908 & 0.905 & 0.906 & 0.542 & 0.499 \\
\hline Inflation & 0.066 & 0.070 & 0.068 & -0.004 & 0.005 \\
\hline
\end{tabular}

Source: Author's calculations based on the IRI and model-simulated data.

Notes: The table compares the estimates of the specification suggested by the Calvo model for the simulated and actual data. The dependent variable is the variance of $\log$ prices, $\sigma^{2}$. Columns (1)-(3) use the data simulated for the monetary shock, the TFP shock, and both of them, respectively. Columns (4) and (5) reproduce column (3) of Table 2. 